J. Clin. Chem. Clin. Biochem.

Vol. 18, 1980, pp. 313-326

\title{
Pankreatische B-Zellen-Peptide: \\ Kinetik und Konzentration von Proinsulin, Insulin und C-Peptid in Plasma und Urin, Probleme der Meßmethoden, klinische Aussage und Literaturübersicht
}

\author{
Von K.-D. Gerbitz
}

Klinisch-chem. Institut, Städtisches Krankenhaus München-Schwabing

(Eingegangen am 13. Juni/29. Oktober 1979)

\section{Herrn Professor Dr. Otto Heinrich Wieland zum 60. Geburtstag gewidmet}

Zusammenfassung: Kinetik und Konzentrationen der in Plasma und Urin meßbaren B-Zellen-Peptide werden anhand einer Übersicht der bisher in der Literatur mitgeteilten Daten erläutert und die möglichen Anwendungsgebiete sowie die klinische Aussagekraft der Methoden diskutiert. Allgemeine Probleme der Meßmethoden für freies und antikörpergebundenes Insulin, Proinsulin und C-Peptid und die möglichen Anwendungsgebiete vor allem im Hinblick auf Diagnostik und Therapie insulinpflichtiger Diabetiker werden dargelegt.

Pancreatic $B$ cell peptides:

Kinetic behaviour and concentrations of proinsulin, insulin and $C$-peptide in plasma and urine, problems of assay methods, clinical significance and literature review

Summary: The kinetics and the concentrations of B-cell peptides in plasma and urine are reviewed. Methodical problems in the determination of proinsulin, free and antibody-bound insulin and C-peptide are discussed, together with the possible application of these methods in the control of insulin-dependent diabetics.

\section{Einführung}

Eine Reihe von in den letzten Jahren entwickelten bzw. verbesserten Methoden hat den labordiagnostischen Bereich der Diabetologie und der ihr verwandten Gebiete deutlich erweitert. Durch geeignete Trennverfahren wurde die radioimmunologische Bestimmung von Insulin auch beim insulinpflichtigen Diabetiker ermöglicht, der in der Regel Antikörper gegen das injizierte artfremde Insulin entwickelt. Radioimmunologische Methoden zur Bestimmung von Proinsulin, der Vorstufe des Insulins, und C-Peptid, dem bei der Umwandlung von Proinsulin zu Insulin abgespaltenen connecting peptide, sind entwickelt und weiter verbessert worden. Eine Aussage über die Restfunktion des diabetischen Pankreas ist damit möglich geworden.

Im folgenden sollen in einem Literaturüberblick die Konzentrationen in Plasma und Urin sowie die Kinetik der B-Zell-Peptide, nachdem sie die B-Zelle verlassen haben, besprochen werden. Allgemeine Probleme der Meßmethoden werden diskutiert und die klinischen Anwendungsgebiete der Verfahiren vor allem im Hinblick auf die Diagnostik und Therapie insulinpflichtiger Diabetiker dargelegt.
Kinetik und Konzentration im Plasma von Proinsulin, Insulin und C-Peptid

Die Primärstruktur von Proinsulin, Insulin und C-Peptid ist in Abbildung 1 angegeben (1). Die Spaltung von Proinsulin innerhalb der B-Zellen der Langerhans'schen Inseln führt zur Bildung von Insulin, C-Peptid und zwei Paaren basischer Aminosäuren $(1,2,3)$. Insulin wird aus der B-Zelle wahrscheinlich aus zwei verschiedenen pools sezerniert, einem rasch verfügbaren, der nach Reiz freigesetzt wird, und einem langșam sezernierenden, möglicherweise Synthese-abhängigen pool, der für die basale Insulinsekretion verantwortlich sein dürte (4). Nach Stimulation der B-Zelle durch intravenöse Verabreichung von Glucose oder Arginin erreicht das C-Peptid/InsulinVerhältnis in der Portalvene nach 90-120 Sekunden etwa den Wert 1, was deutlich macht, daß beide Peptide in äquimolaren Mengen sezerniert werden $(5,6)$. Die Passage durch die Leber führt - in Abhängigkeit von der Konzentration (7) und offensichtlich als Ausdruck seiner Wirkung (8) - beim Insulin zu einer Extraktion von 50-70\% $(7,9-14)$, wogegen die hepatische Extraktion von C-Peptid nur gering ist (11). Insulin wird mit einer Halbwertszeit von etwa 5 Minuten $(15,16)$ aus dem zirkulierenden Blut entfernt. Nach neueren Modell- 


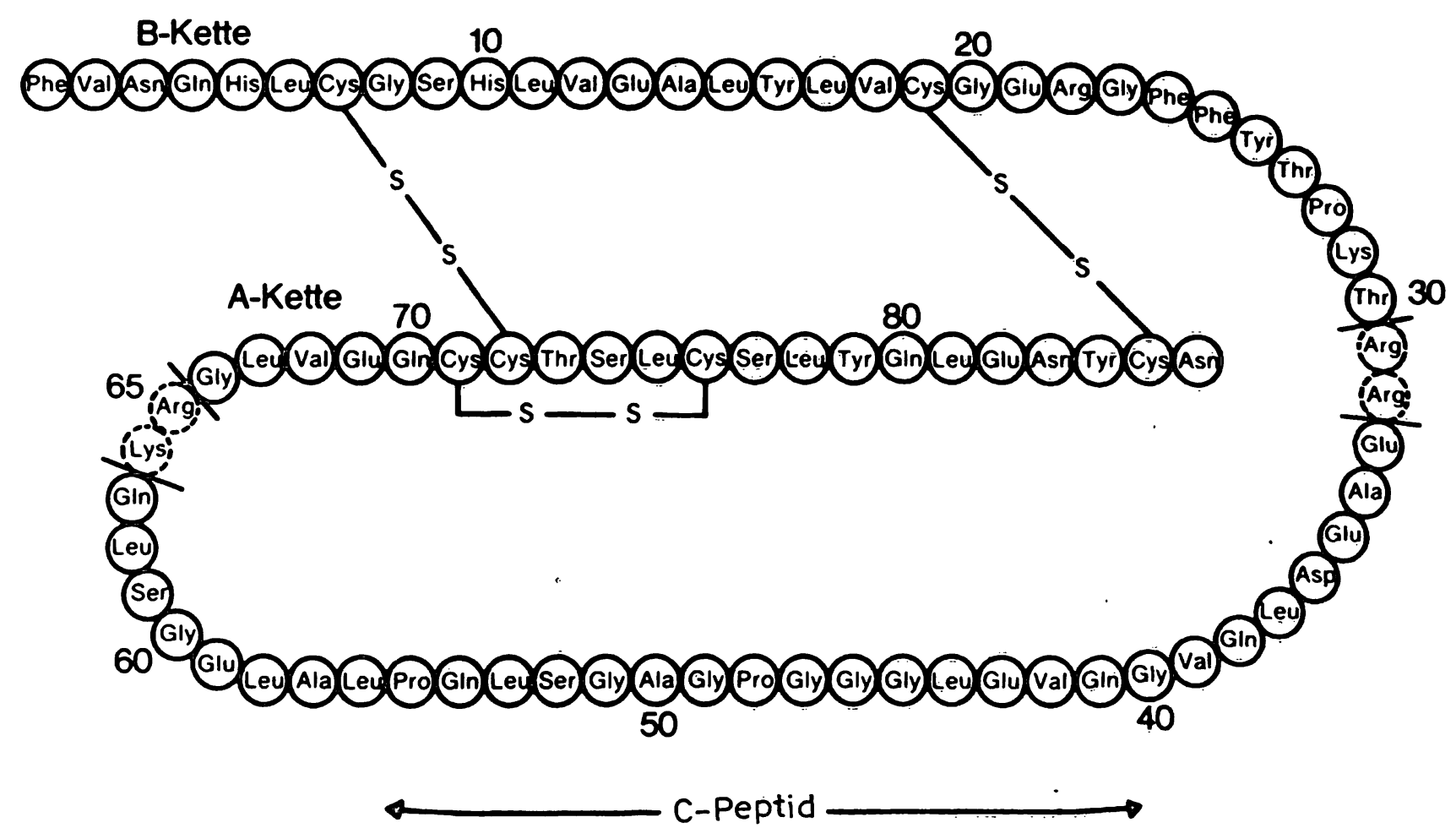

Abb. 1. Aminosäuresequenz des menschlichen Proinsulins. Die bei der Spaltung von Proinsulin in Insulin und C-Peptid freiwerdenden Aminosäurepaare der Positionen 31, 32 und 64, 65 sind bisher beim Menschen nicht identifiziert. Aus Analogie zu allen bisher aufgeklärten Aminosäuresequenzen verschiedener Proinsuline ist die Paarung Arg-Arg und Lys-Arg wahrscheinlich. Das menschliche Insulinmolekül unterscheidet sich in Position 30 vom Schweine-Insulin (Thr statt Ala) und in den Positionen 8, 10 und 30 vom Rinder-Insulin.

Position 1 (Phenylalanin $)=$ N-terminal; Position $86($ Asparagin $)=$ COOH-terminal

studien $(13,17)$ sind neben dem Plasmapool wenigstens zwei weitere Verteilungsräume anzunehmen, ein mit dem Plasma schnell austauschendes Kompartiment, das möglicherweise durch die Organe Leber, Herz und Niere repräsentiert wird, und ein langsam austauschendes Kompartiment, das im wesentlichen den Organen Muskel, Fettgewebe und Haut entsprechen dürfte. C-Peptid wird mit einer Halbwertszeit von 11-33 Minuten aus dem Plasma entfernt (18-20). Die Unterschiede in der hepatischen Extraktion und den metabolischen Clearance-Raten zwischen Insulin und C-Peptid führen dazu, daß sich das äquimolare Sekretionsverhältnis beider Peptide in der Peripherie nicht widerspiegelt $(20,21)$. Die unterschiedliche Verschwinderate ist überdies kein konstanter Faktor, sondern schwankt nach neueren Untersuchungen stark $(20,21)$. Peripher wird im Nüchternzustand ein C-Peptid/Insulin-Verhältnis zwischen 3-17 angegeben (21), so daß eine genaue Kalkulation der Konzentration des endogenen Insulins aus der Konzentration des C-Peptids nicht möglich ist. Das C-Peptid/Insulin-Verhältnis ist überdies verschoben bei Erkrankungen derjenigen Organe, die im wesentlichen für den Abbau des jeweiligen Peptids verantwortlich sind (C-Peptid: Niere; Insulin:Leber).

Proinsulin wird aus dem Pankreas im gleichen Verhältnis zu Insulin und C-Peptid ausgeschüttet, wie es in der B-
Zelle vorliegt - etwa $2,5-9 \%$ des immunoreaktiven Insulins (6). Peripher spiegelt sich dieses Verhältnis aufgrund des langsameren Metabolismus von Proinsulin gegenüber Insulin nicht wieder $(15,16)$. Die Halbwertszeit von Proinsulin im Plasma liegt zwischen 17-26 Minuten $(15,16)$. Beim Gesunden beträgt der Proinsulinanteil am gesamten peripher meßbaren immunoreaktiven Insulin zwischen 0-22\%(21-24). Das Proinsulin/InsulinVerhältnis steigt mit dem Alter (22), bei schwerer Hypokaliämie (25), beim Phäochromocy tom (26), bei chronischen Nierenerkrankungen (27) und infolge der Bindung an Antikörper beim insulinpflichtigen Diabetiker an (21, 28). Gabby et al. (29) beschrieben 1976 eine Familie, bei der eine autosomal vererbte Anomalie in Synthese oder Spaltung des Proinsulins zu einer familiären Hyperproịnsulinämie führte.

Alle drei B-Zellen-Peptide werden durch die Niere in den Harn ausgeschieden. Aufgrund der unterschiedlichen Ausscheidung - nur etwa 0,1\% des vom Pankreas sezernierten Insulins erscheinen im Urin (30), dagegen 5-20\% des pankreatischen C-Peptids $(19,20,30,36-39)$ - ist die Messung von Insulin und Proinsulin im Urin zwar möglich (31-35), aber wenig sinnvoll, da im C-Pẹptid eine verläßlichere Kenngröße gegeben ist. Die renale C-Peptid-Clearance beträgt $5,1 \pm 0,6 \mathrm{ml} / \mathrm{min}$, ist damit etwa fünfmal so hoch wie die von Insulin $(19,20,30)$ 
und weitgehend unabhängig von der endogenen Kreatinin-Clearance (30). Dennoch kommt es im terminalen Nierenversagen und bei Dialysepatienten zu einer deutlichen Einschränkung der C.Peptid-Clearance (37). Die C-Peptidausscheidung im Urin geht den Konzentrationen im Plasma weitgehend parallel - sowohl unter Basal- als auch unter Stimulationsbedingungen (38) und ist somit auch ein Maß für die Funktion der BZelle.

Metabolismus und Konzentrationen der einzelnen B-Zellen-Peptide im Plasma unterscheiden sich beim insulinpflichtigen Diabetiker deutlich von den beim Gesunden dargestellten Verhältnissen. Vier Gründe sind hierfür im wesentlichen verantwortlich:

\section{Die Insulinproduktion des Pankreas eines juvenilen Diabetikers ist vermindert oder vollständig erloschen}

Das Versiegen der endogenen Insulinproduktion der B-Zelle ist der pathogenetische Ausgang für die Manifestation des juvenilen Diabetes. Die Einschränkung der Insulinsynthese erfolgt in der Regel nicht abrupt, sondern über Wochen und Monate (40). Auch nach Manifestation des Diabetes persistiert die endogene Restproduktion des Pankreas an Insulin häufig über einen Zeitraum von mehreren Jahren, bis sie schließlich ganz zum Erliegen kommt. Fälle, bei denen sich auch nach zehnjähriger und längerer Diabetesdauer anhand meßbarer C-Peptid-Konzentrationen eine endogene Restproduktion nachweisen läßt, sind keine Seltenheit (41-44). Wir konnten vor kurzem einen juvenilen Diabetiker mit 28 Jahre dauerndem Diabetes untersuchen, der normale Nüchternwerte für C-Peptid zeigte und dessen B-Zelleninsuffizienz erst nach einem oralen Glucosetoleranztest sichtbar wurde (45).

Zumindest in der Anfangsphase besteht bejm juvenilen Diabetiker in der Regel nur ein relativer Insulinmangel. Die Dauer der Persistenz der endogenen Restproduktion scheint vom Manifestationslater abzuhängen (40). Beginnt der Diabetes mit Ketoacidose und schwerer Hyperglykämie, ist meist kēin C-Peptid nachweisbar (46), das Pankreas kann sich aber erholen und während der Remissionsphase bis in den Normbereich reichende C-Peptid-Sekretion zeigen (46-48). Eine Reihe von Veröffentlichungen der letzten Jahre hat deutlich gemacht, daß die Persistenz der endogenen Restproduktion an Insulin von entșcheidendèr Bedeutung für Therapie und Güte der Einstellung des Diąbetikers ist (Ubersicht bei l.c. $(49,50))$.

\section{Der Ausgleich des Insulinmangels durch exogenes Insulin kann in der Regel nur systemisch erfolgen}

Beim Gesunden gelangt das auf Reiz ausgeschiedene Insulin via vena portae unmittelbar in die Leber als dem Schlüsselorgan der Glucosehomöostase. Die subcutane oder intramụskuläre Veräbreichung von Insulin beim juvenilen Diabetiker führt dagegen zuerst zu einem Konzentrationsanstieg des Insulin im gesamten systemischen Kreislauf. Die Unwägbarkeiten der Absorptionsraten des s.c. oder i.m. applizierten Insulin, die vom Injektionsort und dessen Durchblutung (51-56) und der verwendeten Insulinart abhängen (57), erschweren eine im Hinblick auf die postprandialen Glucoseanstiege zeit- und dosisgerechte Insulinapplikation.

\section{Die Bildung von Insulin-Antikörpern}

In der Regel induziert die Injektion von artfremdem Insulin beim Diabetiker die Bildung von Insulin-Antikörpern. Je nach Reinheit des applizierten Insulins lassen sich bei Verwendung der sog. konventionellen, also nicht hochgereinigten Insuline, nicht nur Antikörper gegen das Insulinmolekül selbst nachweisen, sondern auch gegen die in diesen Insulinpräparationen teilweise vorhandenen Verunreinigungen wie Proinsulin, Insulineinzelketten, ja selten auch gegen andere pankreatische Hormone wie Glucagon, pancreatic polypeptide und vasoactive intestinal polypeptide (VIP) (58). Die Frage, ob die Verwendung der chromatographisch hochgereinigten Insuline zu einer Verringerung der Antigenität des Insulinmoleküls selbst geführt hat, wird in der Literatur kontrovers beantwortet (Übersicht siehe bei 1.c. (59)). Unumstritten ist aber, daß durch die bessere Reinigung der Anteil der Verunreinigung mit Proinsulin zurückgegangen ist. Abbildung 2 gibt eine schematische Darstellung der möglichen B-Zellenpeptidfraktionen im Plasma eines Diabetikers, der über endogene Restproduktion an Insulin verfügt und ein nicht hochgereinigtes Rinder-Schweine-Mischinsulin injiziert. Nicht aufgeführt sind hierbei die vor kurzem von De Haen et al. beschriebenen verschiedenen Proinsulin-InsulinIntermediate im menschlichen Plasma (60). Die Verunreinigungen mit Rinder- und Schweine-Proinsulin führen zur Bildung von spezies-spezifischen Antikörpern gegen das jeweilige Proinsulin und die C-Peptid-Komponente (61). Aufgrund der gegenüber menschlichem C-Peptid sehr unterschiedlichen Aminosäuresequenz dieser Proinsuline bzw. deren C-Peptid-Komponente binden die dagegen gebildeten Antikörper kein menschliches Proinsulin und C-Peptid $(62,63)$. Der gegen die artfremden Insulinmoleküle gebildeten Antikörper bindet dagegen sowohl dạs injizierte Rinder- und Schweine-Insulin je nach Spezies mit möglicherweise unterschiedlicher Affinität (64-66) - als auch das endogen sezernierte humane Insulin und Proinsulin (67). Obwohl in der Regel bedeutend weniger Proinsulin als Insulin oder CPeptid von der B-Zelle sezerniert wird, ist die periphere Konzentration an Proinsulin aufgrund seiner Bindung à Antikörper beim insulinpflichtigen Diabetiker höher als die des C-Peptid $(21,29,67)$. Der Proinsulinanteil am gesamt meßbaren immunoreaktiven Insulin kann, wie neueste Studien von Heding et al. (21) gezeigt haben, bei Diabetikern, deren Pankreas noch Insulin produziert, bis zu $93 \%$ beitragen. Die Konzentrationsverhältnisse 


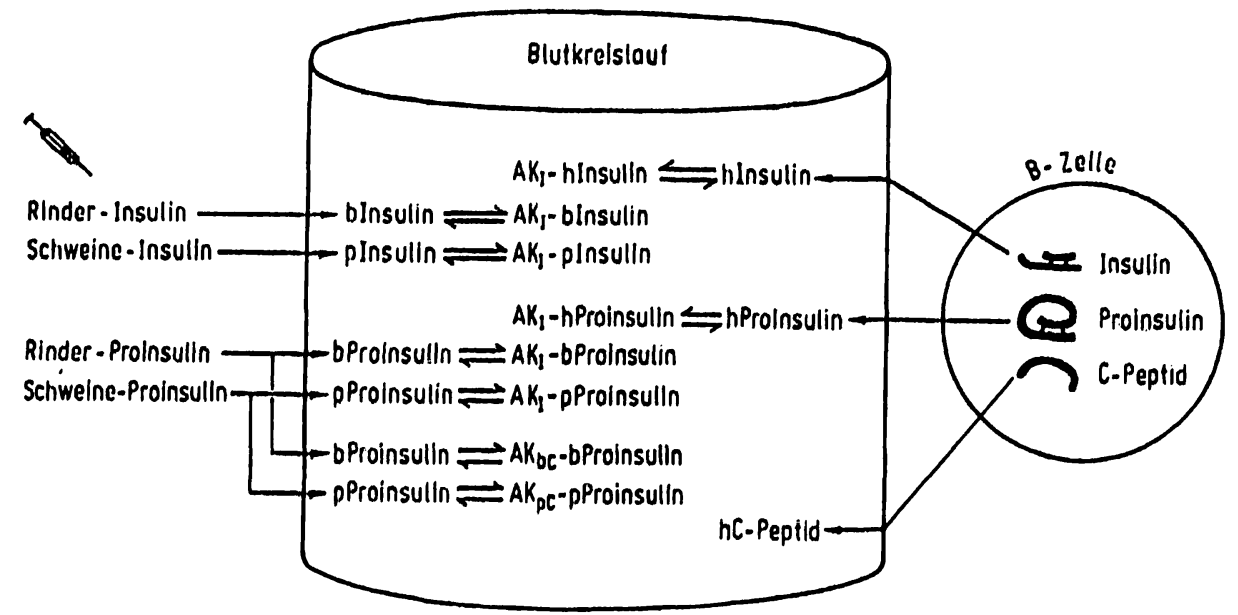

$\Lambda$ bb. 2. Freic und antikörpergebundene Fraktionen der B-Zellen-Peptide im Plasma von Diabetikern, die über eine endogene Restpro. duktion an Insulin verfugen und ein nicht hochgereinigtes Rinder-Schweine-Mischinsulin injizieren.

$h=$ human (Mensch); $b=$ bovine (Rind); $p=$ porcine (Schwcin); $A K_{I}=$ Antikörper gegen Insulinmolekül; $A K_{b C}=$ Antikörper gegen Rinder-C-Pcptid-Scgment; $A K_{p C}=$ Antikörper gegen Schweinc-C-Peptid-Segment.

Schicma inodifizicrt nach l.c. (61).

zwischen frciem und antikörpergebundenem Insulin hïngen in vivo sowohl von der Menge und Affinität des gebildeten Antikörpers als auch von der Absorptionsrate des injizicrten Insulins und nicht zuletzt von der unterschiedlichen Verschwinde- und Abbaurate beider Insulinfraktionen ab. In der Regel ist beim Diabetiker gegenüber der Konzentration an freicm Insulin die 5-20 $(-100)$ fache Konzentration an Antikörper gebunden $(68-74)$. Freies Insulin hat cine Halbwertszeit von etwa 5 Minuten im Plasma $(15,16)$, antikörpergebundenes Insulin soll dagegen erheblich länger persistieren (75). Der Antikörper schützt also einerseits Insulin vor dem Abbau, blockicrt aber andererseits dessen Wirkung an der Erfolgszelle, da nach allgemeiner Auffassung gebundenes Insulin nicint wirksam ist. Berson \& Yalow (64) haben gezeigt, daß die divalenten Antikörper vom Typ des $\lg G$ Insulin mit Bindungsstellen unterschiedlicher Affinität binden (low and high affinity sites). Nach Assoziation- und Dissoziationsstudien in vitro (75-77) ist der Austausch an der low affinity site ein Minutenpro$z e ß$, wogegen Bindung und Dissoziation von Insulin an der high affinity site deutlich langsamer vorsichgehen. Vor kurzem konnten wir zcigen, daß auch in vivo die Konzentrationsïnderungen des freien Insulins nach in travenöser Gabe von Insulin von schnellen Konzentrationsünderungen eines Teils des antikörpergebundenen Insulins begleitet sind (72). Uberdies fand sich eine enge Korrelation der in vivo zu bestimmenden Konzentrationsverhältnisse zwischen gebundenem und freiem Insulin (b/f ratio) auf der einen Seite mit den aus Sättigungsanalysen über Scatchard-plots zu crmittelnden Affinitä tscharakte ristika (Bindungskapazitäten und Affinitätskonstanten) der beiden Bindungsstellen auf der anderen Seite (50). Mit anderen Worten: die Lage des dynamischen Fließgleichgewichts von der Ab- sorption des exogenen Insulins bzw. der Sekretion des endogenen Insulins über dic Assoziations- und Dissoziationsprozesse am Antikörper bis hin zu Rczeptorbindung und Abbau des Insulins und somit auch die Konzentration der Kenngröße "freies Insulin" wird wesentlich durch Affinität und Bindungskapazität der Insulinantikörper mitbestimmt. Aufgrund der Komplexität dieser Vorgänge crscheint es nicht verwunderlich, daß die Aussagen über die Wertigkeit von Antikörpern für die Therapie des Diabetikers in der Literatur äußerst kontrovers sind. Während einzelne Autoren (78-80) einen stabilisierenden Effekt der Antikörper vor allem auf die Einstellbarkeit des "brittle diabetes" beschrieben, kommen andere (81-89) zu genau gegenteiligen Ergebnissen. Aus den meisten Arbeiten zu diesem Thema lassen sich kcine eindeutig definierbaren Ein flüsse der Insulin-Antikörper auf die Einstellbarkeit des Diabetikers und den täglichen Insulinbedarf ableiten (68-74, 90-96).

\section{Die periphere Resistenzlage}

Pathogenetisch ist der juvenilc Diabetiker gekennzeichnet durch einen relativen oder absoluten Mangel an endo. genem Insulin. In der Ära der Insulintherapie ist es dennoch nur bedingt richtig, von einem Insulinmangeldiabetes zu sprechen. Infolge der therapeutischen Substitution haben die meisten insulinpflichtigen Diabetiker eine Hyperinsulinämie (siehe Tab. 1). Dies hat unter anderem zu Überlegungen über den Zusammenhang zwischen Hyperinsulinämie und Makroangiopathie geführt (97). Die tägliche Insulinproduktion des gesunden Pankreas beträgt zwischen 20-30 Einheiten (98). Diabetiker ohne endogene Restproduktion - gemessen am Fehlen von C.Peptid - spritzen in der Regel mehr. .. 
Tab. 1. Insulin in Plasma oder Serum*).

\begin{tabular}{|c|c|c|c|c|c|}
\hline Referenz & $\begin{array}{l}\text { freies Insulin } \\
(\mathrm{mU} / \mathrm{l})\end{array}$ & & $\begin{array}{l}\text { Gesamt-Insulin } \\
(\mathrm{mU} / \mathrm{l})\end{array}$ & Personen (n) & Bemerkungen \\
\hline $\begin{array}{l}\text { Nakagawa et al. } \\
1973(101)\end{array}$ & $\begin{array}{r}19,7 \pm 10,3 \\
7,3 \pm 4,3\end{array}$ & $\begin{array}{l}\text { (SD) } \\
(\mathrm{SD})\end{array}$ & & $\begin{array}{l}\text { Normalpersonen } \\
\text { juv. Diabetiker (57) }\end{array}$ & $\begin{array}{l}\text { nüchtern } \\
\text { nüchtern }\end{array}$ \\
\hline $\begin{array}{l}\text { Gennaro } \\
\& \text { VanNorman } \\
1975(69)\end{array}$ & $27,1(10-72)$ & & $1959(67-9500)$ & Insulinpfl. Diabetiker (20) & nüchtern \\
\hline $\begin{array}{l}\text { Lewis et al. } \\
1976(131)\end{array}$ & $\begin{array}{l}24,4 \pm 2 \\
42,4 \pm 5,1\end{array}$ & $\begin{array}{l}\text { (SEM) } \\
\text { (SEM) }\end{array}$ & & $\begin{array}{l}\text { gesunde Schwangere (6) } \\
\text { diabet. Schwangere (7) }\end{array}$ & $\begin{array}{l}24 \text { h-Durchschnittswerte } \\
24 \text { h-Durchschnittswerte } \\
\text { bei guter Kontrolle }\end{array}$ \\
\hline $\begin{array}{l}\text { Olefsky et al. } \\
1977(148)\end{array}$ & $\begin{array}{r}7,1 \pm 1(1-11) \\
13,2 \pm 2(1-26) \\
18,3 \pm 3(1-32)\end{array}$ & & & $\begin{array}{l}\text { Normalpersonen (24) } \\
\text { lat. Diabetiker (14) } \\
\text { juv. Diabetiker ( } 33 \text { ) }\end{array}$ & $\begin{array}{l}\text { nüchtern } \\
\text { nüchtern } \\
\text { nüchtern }\end{array}$ \\
\hline $\begin{array}{l}\text { Kuzuya et al. } \\
1976(68)\end{array}$ & $10(2,5-25,5)$ & & $1765(193-3911)$ & juv. Diabetiker (11) & nüchtern \\
\hline \multirow{4}{*}{$\begin{array}{l}\text { Gerbitz } \\
\& \text { Kemmler } \\
1979(50)\end{array}$} & $24,6(6-58)$ & & & $\begin{array}{l}\text { juv. Diabetiker } \\
\text { mit C-Peptid (8) }\end{array}$ & nüchtern \\
\hline & $39,1 \pm 6,9$ & (SEM) & $460(22-1700)$ & $\begin{array}{l}\text { juv. Diabetiker } \\
\text { mit C-Peptid (8) }\end{array}$ & 24 h-Durchschnittswerte \\
\hline & $19,1(8-34)$ & & & $\begin{array}{l}\text { juv. Diabetiker } \\
\text { ohne C-Peptid ( } 8 \text { ) }\end{array}$ & nüchtern \\
\hline & $21,2 \pm 4$ & (SEM) & $277(39-1173)$ & $\begin{array}{l}\text { juv. Diabetiker } \\
\text { ohne C-Peptid ( } 8 \text { ) }\end{array}$ & 24 h-Durchschnittswerte \\
\hline
\end{tabular}

*) in die Tabelle wurden nur Werte aufgenommen, die nach Fällung des Plasmas mit Polyethylenglykol gewonnen wurden.

Der erhöhte Insulinbedarf, die daraus resultierende Hyperinsulinämie, die auch bei i.v. Gabe von Insulin zur Normalisierung der Glucosekonzentration unterschiedliche, notwendige Insulindosis (72), Fälle mit stark erhöhten freien Plasmainsulinkonzentrationen ohne Hypoglykämie $(45,69)$ und die teilweise extrem variierende Ansprechbarkeit des "brittle diabetes" auf Insulin haben die Resistenzlage der Insulin-sensitiven Gewebe beim Diabetiker in den Vordergrund des Interesses gerückt. Der Rezeptorpool der peripheren Erfolgszelle ist in seiner Gesamtheit bisher nicht kalkulierbar. Sicher ist, daß er große Mengen an Insulin binden und im Sinne eines Reservoirs möglicherweise wieder abgeben kann (14). Es ist däher für die klinisch-experimentelle Diabetologie eine der Aufgaben der Zukunft, die Beziehungen zwischen peripherer Resistenzlage und den Konzentrationen der B-Zellen-Peptide im Plasma zu klären.

Anmerkungen zur Methodik der Bestimmung von Insulin, C-Peptid und Proinsulin

\section{Trennung von frèiem und antikörpergebundènem Insulin}

Die Konzentration dẹ an Antikörper gebundeñen zirku-

lierenden Insulins ist in der Regel beim insulinpflichtigen Diabetiker erheblich höher als die des freien Insulins.

Freies Insulin wird als die wirksame Form angesehen. Bei der Messung von Insulin beim Diabetiker ist daher eine Trennung beider Fraktionen notwendig. 1971 beschrieben Desbuquois \& Aurbach $(99,100)$, daß freie und Anti- körper-gebundene Peptidhormone durch Polyethylenglykol getrennt werden können. 1973 modifizierten Nakagawa et al. (101) diese Methode zur Trennung von freiem und antikörpergebundenem Insulin. In der Zwischenzeit sind weitere Modifikationen und erste Erfahrungen beschrieben worden (68-70). Die von uns verwendete Modifikation (71) ist schematisch in Abbildung 3 angegeben.

Bestimmung des freien Insulins und des GesamtInsulins in Polyethylenglykol-Extrakten

Die Bestimmung beider Insulinfraktionen in den jeweiligen Ưberständen nach Fällung mit Polyethylenglykol kann nach unseren eigenen und den in der Literatur mitgeteilten Erfahrungen $(68-71,101)$ sowohl mit den verschiedenen kommerziell vertriebenen Radioimmunoassays für Insulin als auch mit selbsthergestellten Antiseren vorgenommen werden. Prinzipiell ist es dabei gleichguiltig, ob nach der Inkubationszeit die Trennung von gebundenem und freiem Insulin im Test durch Adsorption an Kohle o.a., Doppelantikörper-Methode oder andere Fällungsverfahren, z. B. mit Polyethylenglykol erfolgt, sofern folgende Punkte berücksichtigt werden:

- die Konzentration an Polyethylenglykol muß in Standards und Proben die gleiche sein, da Polyethylenglykol zu einer, wenn auch meist geringgradigen Verschiebung der Standardkurve führen kann. 
Gesamt-Insulin

Freies Insulin

Schritt 1

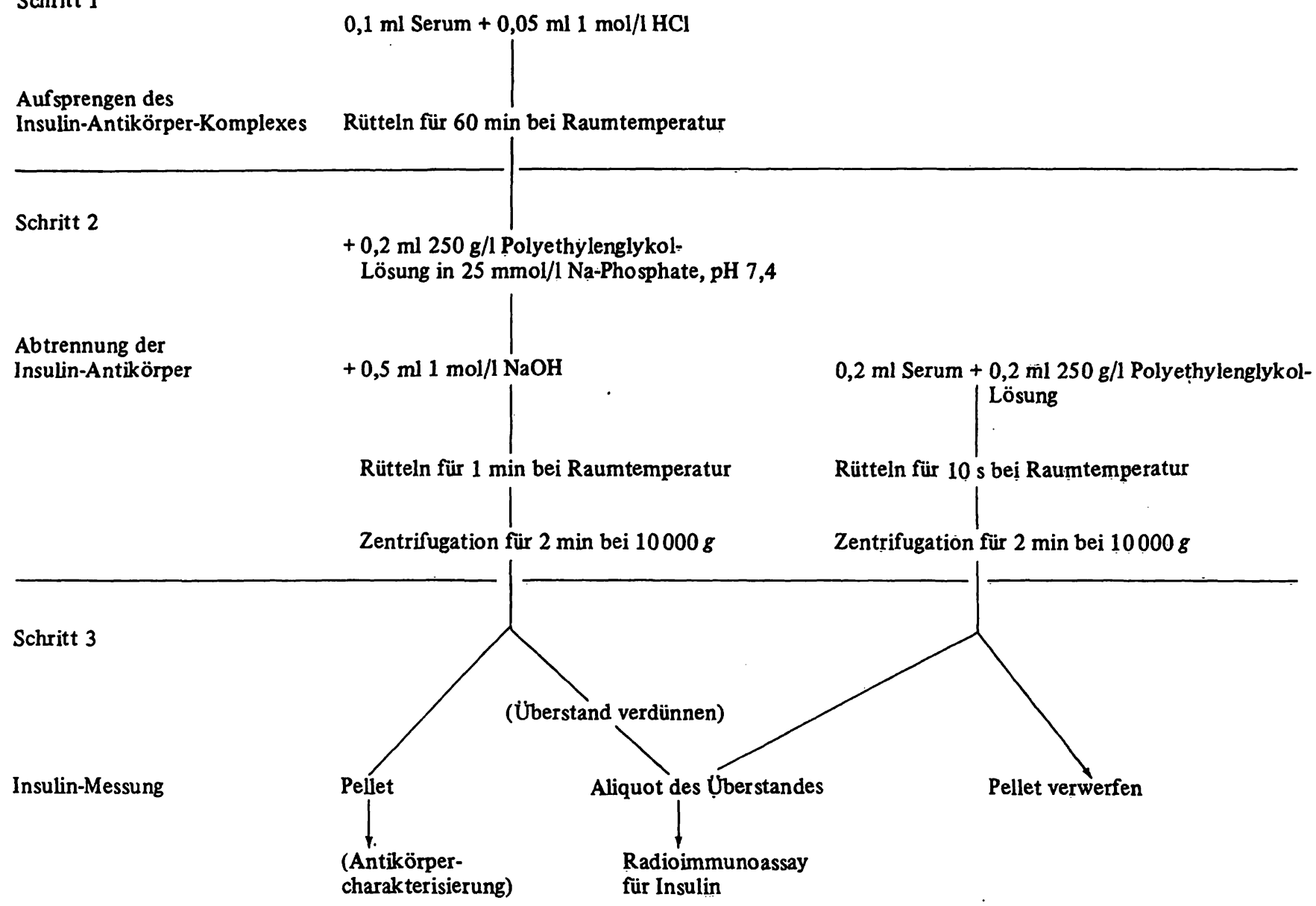

Abb. 3. Schema der Probenvorbereitung zur Messung von Gesamt-Insulin und freiem Insulin in Serum und Plasma.

- die Konzentration an Polyenthylenglykol soll während der Inkubationszeit nicht höher als $4 \%$ sein, da es sonst schon während der Inkubation zur Präzipitation kommen kann.

In unserer Hand hat sich auch im radioimmunologischen Test die Trennung durch Fällung mit Polyethylenglykol (Zugabe eines dem Ansatzvolumen gleichen Volumens an Polyethylenglykol-Lösung - $25 \mathrm{~g} / \mathrm{dl}$ ) als schnelle und präzise Methode bewährt. Um eine vollständige Fällung des im Testansatz gering konzentrierten Antikörperproteins zu erreichen, geben wir unmittelbar nach Zugabe von Polyethylenglykol $0,05 \mathrm{ml}$ an insulinfreiem Normalserum oder menschlichem Gammaglobulin (Beriglobin) zu.

Einzelne Antiseren können unterschiedliche Kreuzreaktivität mit den verschiedenen Insulinen zeigen. $\mathrm{Da}$ im Patientenplasma Rinder-, Schweine- und Human-Insulin vorliegen können, ist die Verwendung eines zu $100 \%$ mit den verschiedenen Speziesinsulinen kreuzreagierenden Antiserums notwendig. Generell ist die Kreuzreaktivität des Antiserums vorher auszutesten.
- die für die Standardḳurve im Insulintest verwendeten Standards sollten in Serum angesetzt vorliegen. Zumindest ist für jeden Test zu prüfen, ob die Standardkurven in wäßrigen, in der Regel Albumin enthaltenden Medien und Serum deckungsgleich sind. Insulinfreies Serum läßt sich durch Zusatż von $0,02 \mathrm{ml}$ einer hämolysierten Erythrocytensuspension zu $1 \mathrm{ml}$ Serum herstellen. Inkubation bei $37^{\circ} \mathrm{C}$ über Nacht zerstört durch Wirkung der Erythrocyten-Insulinase (102) das vorhandene Insulin: Das Enzym wird durch nachfolgende Inkubation des Ansatzes für 1 Stunde bei $56^{\circ} \mathrm{C}$ zerstört.

- zur Bestimmung des freien Insulins sollten hochaffine Antiseren verwendet werden, die eine sichere Analytik auch im Bereich bis $10 \mathrm{mU} / 1$ erlauben.

Die Konzentration an Antikörperr-gebundenem Insulin errechñet sich als Differenz aus Gesamt-Insulin und freiem Inșulin.

Etwaige Störmöglichkeiten der Fällungsmethode mit Polyethylenglykol wurden ausführlich untersucht 
(68-70, 73, 99-102). Asplin et al. (73) verglichen die Ergebnisse der Bestimmung von freiem Insulin und Gesamt-Insulin in Polyethylenglykol-Extrakten mit den Ergebnissen nach Gleichgewichtsfiltration an Sephadex G-50 und fanden nahezu identische Werte für GesamtInsulin, wogegen die Werte für freies Insulin nach Gel-Filtration sowohl gegenüber der Fällungsmethode mit Polyethylenglykol als auch gegenüber der Ethanolfällung (74) niedriger waren und stärker streuten. Eine ausreichende Erklärung hierfür ist bisher nicht gefunden. Obwohl die von Asplin et al. verwendete Gleichgewichtsfiltration von der Theorie her als Referenzmethode angesehen werden kann, ist sie in der Ausführung so aufwendig, daß der Referenzcharakter der Methode in der Hand eines weniger Erfahrenen durch die methodischen Schwierigkeiten beeinträchtigt wird. Eine Dissoziation des Insulins vom Antikörper während der Fällung mit Polyethylenglykol - und damit eine fälschliche Erhöhung der Werte für freies Insulin - ist nach unseren Untersuchungen (70) nicht gegeben.

Ebenso konnte die von Kuzuya et al. mitgeteilte (68) zeitabhängige Dissoziation von gebundenem Insulin nach Auftauen eingefrorener Seren von uns nicht bestätigt werden (70).

\section{Insulin-Antikörper}

Die Fällungsmethode mit Polyethylenglykol kann auch zur Charakterisierung der Insulinantikörper verwendet werden (Bestimmung der Bindungskapazitäten und Affinitätskonstanten). Die genaue Prozedur ist vor kurzem von uns beschrieben worden (70).

\section{C-Peptid}

Eine Reihe von radioimmunologischen Testverfahren zur Bestimmung der Immunoreaktivität des C-Peptids (CPR) ist in den vergangenen Jahren beschrieben worden $(63,67,103-109)$. Die in der Literatur mitgeteilten, stark variierenden C-Peptidkonzentrationen bei Nüchternen (siehe $\mathrm{Tab} .2$ ) lassen vermuten, daß neben der unterschiedlichen Sensitivität der verwendeten Antiseren auch Unterschiede in der Spezifität vorhanden sind. In einer vergleichenden Studie mit sieben verschiedenen C-Peptid-Antiseren konnten Faber et al. (109) nachweisen, daß Antiseren mit hoher unspezifischer TracerVerdrängung hohe C-Peptidwerte ergeben. Die unspezifische Tracer-Verdrängung eines Antiserums variiert überdies von Probe zu Probe, so daß die Autoren vorschlagen, durch Austestung mehrerer C-Peptid-freier Proben eine durchschnittliche unspezifische Verdrängung zu ermitteln. Durch Wiederfindungsversuche, Verdünnungșreihen und die Ermittlung von realen Nullwerten in Proben von langjährigen Diabetikem ist die Spezifität des verwendeten Antiserums zu testen. Wahrscheinlich ist, daß die Heterogenität des im Plasma auftretenden C-Peptids $(110,111)$ und die daraus möglicherweise resultierende unterschiedliche Immunreaktivität zusätzlich für den weiten Bereich der in der Literatur mitgeteilten C-Peptidkonzentrationen verantwortlich ist. Antiseren gegen den connecting peptideAnteil des Proinsulins (CPR) erfassen sowohl das abgespal tene C-Peptid als auch intaktes Proinsulin mit von Antiserum zu Antiserum variierender Affinität (109). Bei Normalpersonen ist die Proinsulin-Konzentration zu gering, um signifikante Verfälschungen der C-Peptidwerte zu ergeben (109). Da die Proinsulin-Konzentration mit dem Alter ansteigt (22), bei schweren Nierenerkrankungen (27), Hypokaliämie (25) und beim Phäochromocytom (26) erhöht ist, ist die Verwendung eines möglichst geringgradig mit Proinsulin kreuzreagierenden C-PeptidAntiserums zu empfehlen. Die Antikörperfixierung des Proinsulins beim insulinpflichtigen Diabetiker, die zu einer starken Erhöhung der Proinsulin-Konzentration führen $\operatorname{kann}(21,28)$, macht die Abtrennung des antikörpergebundenen Proinsulins notwendig. In Ubereinstimmung mit Kuzuya et al. (68) konnten wir vor kurzem zeigen (50), daß auch hier die Fällung mit Polyethylenglykol zu einer quantitativen Abtrennung des antikörpergebundenen Proinsulins führt, wogegen C-Peptid im Überstand bleibt und radioimmunologisch bestimmt werden kann. Der Einfluß von Polyethylenglykol auf die C-Peptid-Standardkurve ist zu prüfen.

Weitere mögliche Fehlerquellen bei der C-Peptidbestimmung seien hier kurz aufgeführt (112):

- fehlende Ubereinstimmung in der Immunoreak tivität des verwendeten Antiserums zwischen synthetischen Standards und natürlichem, menschlichen C-Peptid (113-118).

Aufgrund fehlender Kreuzreaktion von Antiseren verschiedener Spezies mit menschlichem C-Peptid muß zur Immunisierung, als Standard und als radioaktiver Marker menschliches C-Peptid verwendet werden. Da die Reinigung ausreichender Mengen menschlichen C-Peptids schwierig ist, wird in den meisten Tests synthetisches C-Peptid verwendet. Unterschiede in der Immunoreaktivität zwischen synthetischen und natürlichem C-Peptid sind beschrieben (109).

- C-Peptid enthält kein Tyrosin. Diese zur Markierung mit ${ }^{125}$ I notwendige Aminosäure muß erst ins Molekül eingeführt werden. Unterschiede in der Bindung zwischen markiertem und unmarkiertem Antigen und zwischen verschiedenen markierten synthetischen C-PeptidChargen sind beschrieben (109).

Der C-Peptid-Gehalt von Plasmaproben nimmt bei Lagerung in Abhängigkeit von der Temperatur ab. Da der Grad der zu messenden Abnahme der C-Peptid-Reaktivität von der Art des verwendeten Antiserums abhängt (109), ist wahrscheinlich, daß die lagerungsbedingte Veränderung des C-Peptid-Moleküls nicht von allen Antiseren in gleicher Weise erkannt wird. 
Tab. 2. C-Peptid und Proinsulin in Plasma oder Serum.

\begin{tabular}{|c|c|c|c|c|}
\hline Referenz & $\begin{array}{l}\text { C-Peptid } \\
\text { (nmol/l) }\end{array}$ & $\begin{array}{l}\text { Proinsulin } \\
(\mathrm{nmol} / \mathrm{l})\end{array}$ & $\begin{array}{l}\text { Personen } \\
\text { (n) }\end{array}$ & Bemerkungen \\
\hline $\begin{array}{l}\text { Block et al. } \\
1972(67)\end{array}$ & $\begin{array}{l}0,43 \pm 0,1 \\
1,47 \pm 0,27 \\
0,9 \pm 0,23 \\
1,67 \pm 0,37\end{array}$ & & $\begin{array}{l}\text { Normalpersonen (9) } \\
\text { Normalpersonen (9) } \\
\text { Altersdiabetiker (11) } \\
\text { Altersdiabetiker (11) }\end{array}$ & $\begin{array}{l}\text { nüchtern } \\
1 \mathrm{~h} \text { nach } 100 \mathrm{~g} \text { Glucose oral } \\
\text { nüchtern } \\
2 \mathrm{~h} \text { nạch } 100 \mathrm{~g} \text { Glucose oral }\end{array}$ \\
\hline \multirow[t]{4}{*}{$\begin{array}{l}\text { Heding \& Rasmussen } \\
1975 \text { (106) }\end{array}$} & $\begin{array}{l}0,37 \pm 0,02(S D) \\
2,53 \pm 0,2 \quad(S D)\end{array}$ & & $\begin{array}{l}\text { Normalpersonen (14) } \\
\text { Normalpersonen (14) }\end{array}$ & $\begin{array}{l}\text { nüchtern } \\
1 \text { h nach Glucose }(1,75 \mathrm{~g} / \mathrm{kg})\end{array}$ \\
\hline & $0,37 \pm 0,04(\mathrm{SD})$ & & $\begin{array}{l}\text { Insulinpflich tige } \\
\text { Diäbetiker vor } \\
\text { Insulin-Behandlung (10) }\end{array}$ & nüchtern \\
\hline & $0,49 \pm 0,05(\mathrm{SD})$ & & $\begin{array}{l}\text { Insulinpflichtige } \\
\text { Diabetiker vor } \\
\text { Insulin-Behandlung (10) }\end{array}$ & $1 \mathrm{~h}$ nach Glucose $(1,75 \mathrm{~g} / \mathrm{kg})$ \\
\hline & $\begin{array}{l}0,86 \pm 0,17(\mathrm{SD}) \\
2,49 \pm 0,31(\mathrm{SD})\end{array}$ & , & $\begin{array}{l}\text { Altersdiabetiker (9) } \\
\text { Altersdiabetiker (9) }\end{array}$ & $\begin{array}{l}\text { nüchtern } \\
1 \mathrm{~h} \text { nach Glucose }(1,75 \mathrm{~g} / \mathrm{kg})\end{array}$ \\
\hline $\begin{array}{l}\text { Heding } \\
1975 \text { (107) }\end{array}$ & $\begin{array}{l}0,35 \pm 0,09(\text { SD) } \\
2,24 \pm 0,71(\text { SD) } \\
0,21 \pm 0,14(\text { SD) } \\
0,42 \pm 0,24(\text { SD) } \\
0,74 \pm 0,51(\text { SD) } \\
2,34 \pm 1,18 \text { (SD) }\end{array}$ & & $\begin{array}{l}\text { Normalpersonen (24) } \\
\text { Normalpersonen (24) } \\
\text { juvenile Diabet. (17) } \\
\text { juvenile Diabet. (17) } \\
\text { Altersdiabetiker (9) } \\
\text { Altersdiabetiker (9) }\end{array}$ & $\begin{array}{l}\text { nüchtern } \\
1 \text { h nach Glucose }(1,75 \mathrm{~g} / \mathrm{kg}) \\
\text { nụ̈chtern } \\
1 \mathrm{~h} \text { nach Glucose }(1,75 \mathrm{~g} / \mathrm{kg}) \\
\text { nüchtern } \\
1 \text { h nach Glucose }(1,75 \mathrm{~g} / \mathrm{kg})\end{array}$ \\
\hline \multirow[t]{2}{*}{$\begin{array}{l}\text { Horwitz et al. } \\
1975(6)\end{array}$} & $\begin{array}{l}1,2 \pm 0,43(\mathrm{SD}) \\
1,55 \pm 0,62(\mathrm{SD}) \\
1,0 \pm 0,3(\mathrm{SD})\end{array}$ & & $\begin{array}{l}\text { Normalperșonen (6) } \\
\text { Normalpersonen (6) } \\
\text { Normalpersonen (6) }\end{array}$ & $\begin{array}{l}\text { nüchtern (peripheres Blut) } \\
\text { nüchtern (Vena portae) } \\
90 \mathrm{~s} \text { nach } 25 \mathrm{~g} \text { Glucose iv. } \\
\text { (perịpheres Blut) }\end{array}$ \\
\hline & $6,23 \pm 2,47(\mathrm{SD})$ & & Normalpersonen (6) & $\begin{array}{l}90 \text { s nach } 25 \mathrm{~g} \text { Glucose iv. } \\
\text { (Vena portae) }\end{array}$ \\
\hline $\begin{array}{l}\text { Kuzuya et al. } \\
1976(68)\end{array}$ & $\begin{array}{l}0,82 \pm 0,32(S D) \\
2,34 \pm 0,67(S D) \\
0,29 \pm 0,18(S D) \\
0,44 \pm 0,14(S D)\end{array}$ & & $\begin{array}{l}\text { Normalpersonen (19) } \\
\text { Normalpersonen (19) } \\
\text { juv. ketot. Diab. (5) } \\
\text { juv. ketot. Diab. (5) }\end{array}$ & $\begin{array}{l}\text { nüchtern } \\
1 \mathrm{~h} \text { nach } 50 \mathrm{~g} \text { Glucose oral } \\
\text { nüchtern } \\
1 \mathrm{~h} \text { nach } 50 \mathrm{~g} \text { Glucose oral }\end{array}$ \\
\hline $\begin{array}{l}\text { Lewis et al. } \\
1976 \text { (131) }\end{array}$ & $\begin{array}{l}0,84-1,27 \\
0,23 \pm 0,04(\mathrm{SEM}) \\
2,23 \pm 0,5 \quad(\mathrm{SEM}\end{array}$ & & $\begin{array}{l}\text { Ges. Schwangere (6) } \\
\text { diab. Schwangere (4) } \\
\text { diab. Schwangere } \\
\text { vor Insulintherapie }\end{array}$ & $\begin{array}{l}\text { Durchschnittswerte über } 24 \text { Stunden } \\
\text { Durchschnittswerte über } 24 \text { Stunden } \\
\text { Durchschnittswerte über } 24 \text { Stunde }\end{array}$ \\
\hline $\begin{array}{l}\text { Beischer et al. } \\
1976(125)\end{array}$ & $\begin{array}{l}0,6 \pm 0,13(\mathrm{SD}) \\
0,12 \pm 0,47 \\
0,53 \pm 1,3 \\
0,1 \pm 1,4\end{array}$ & & $\begin{array}{l}\text { Normalpersonen (25) } \\
\text { juv. Diabetiker (11) } \\
\text { juv. Diabetiker (4) } \\
\text { Altersdiabetiker (22) }\end{array}$ & $\begin{array}{l}\text { nüchtern } \\
\text { nüchtern } \\
\text { nüchtern während Remission } \\
\text { nüchtern }\end{array}$ \\
\hline $\begin{array}{l}\text { Krause et al. } \\
1977 \text { (139) }\end{array}$ & $\begin{array}{ll}0,36-1,19 \\
1,9 \pm 1 & (\mathrm{SEM}) \\
0,8 \pm 1 & (\mathrm{SEM}) \\
1,6 \pm 1,8 & (\mathrm{SEM})\end{array}$ & & $\begin{array}{l}\text { Normalpersonen (130) } \\
\text { Normalpersonen (37) } \\
\text { Altersdiabetiker (19) } \\
\text { Altersdiabetiker (19) }\end{array}$ & $\begin{array}{l}\text { nüchtern } \\
1 \mathrm{~h} \text { nach } 100 \mathrm{~g} \text { Glucose oral } \\
\text { nüchtern } \\
1 \mathrm{~h} \text { nach } 100 \mathrm{~g} \text { Glucose oral }\end{array}$ \\
\hline $\begin{array}{l}\text { Faber \& Binder } \\
1977 \text { (141) }\end{array}$ & $0,27(0,08-0,68)$ & & $\begin{array}{l}\text { Insulinpflichtige } \\
\text { Diabetiker (17) }\end{array}$ & Durchschnittswerte über 24 Stunden \\
\hline $\begin{array}{l}\text { Faber \& Binder } \\
1977(140)\end{array}$ & $\begin{array}{l}0,36(0,26-0,69) \\
1,28(0,91-1,88) \\
0,18(0,05-0,41)\end{array}$ & & $\begin{array}{l}\text { Normalpersonen }(10) \\
\text { Normalpersonen }(10) \\
\text { Insulinpflichtige } \\
\text { Diabetiker (17) }\end{array}$ & $\begin{array}{l}\text { nüchtern̈ } \\
\text { peak nach Glukagonstimulation } \\
\text { nüchtern }\end{array}$ \\
\hline $\begin{array}{l}\text { Faber \& Binder } \\
1977(142)\end{array}$ & $\begin{array}{l}0,36(0,08-0,94) \\
0,34(0,08-0,78) \\
0,36(0,25-0,56) \\
1,14 \\
0,66(0,42-0,91) \\
0,17(0,08-0,45) \\
0,32 \\
0,22(0,07-0,55)\end{array}$ & ' & $\begin{array}{l}\text { Insulinpfl. Diab. (17) } \\
\text { Insulinpfl. Diab. (17) } \\
\text { Normalpersonen (10) } \\
\text { Normalpersonen (10) } \\
\text { Normalpersonen (10) } \\
\text { Insulinpfl. Diab. (17) } \\
\text { Insulinpfl. Diab. (17) } \\
\text { Insulinpfl. Diab. (17) }\end{array}$ & $\begin{array}{l}\text { peak postprandial } \\
\text { peak nach Glucagonstimulation } \\
\text { nüchtern } \\
1 \text { h postprandial } \\
\text { Durchschnittswerte } 8=19 \mathrm{Uhr} \\
\text { nüchtern } \\
1 \text { h postprandial } \\
\text { Durchschnittswerte } 8-19 \mathrm{Uhr}\end{array}$ \\
\hline $\begin{array}{l}\text { Regeur et al. } \\
1978 \text { (155) }\end{array}$ & $0,35(0,18-0,63)$ & & Normalpersonen (27) & nüchtern \\
\hline \multirow[t]{2}{*}{$\begin{array}{l}\text { Ludvigson \& Heding } \\
1976 \text { (43) }\end{array}$} & 0,04 & & juv. Diab., Kinder (62) & $\begin{array}{l}\text { nüchtern, Diabetesdauer: } \\
\text { 3-15 Jahre, } \bar{x} 8 \text { Jahre }\end{array}$ \\
\hline & $0,04-0,17$ & & juv. Diab., Kinder (19) & $\begin{array}{l}\text { nüchtern, Diabetes mit Dauer: } \\
2-11, \bar{x} 4,5 \text { Jahre }\end{array}$ \\
\hline
\end{tabular}


Tab. 2. (continued)

\begin{tabular}{|c|c|c|c|c|}
\hline Referenz & $\begin{array}{l}\text { C-Peptid } \\
\text { (nmol/1) }\end{array}$ & $\begin{array}{l}\text { Proinsulin } \\
\text { (nmol/1) }\end{array}$ & $\begin{array}{l}\text { Personen } \\
\text { (n) }\end{array}$ & Bemerkungen \\
\hline & $0,18-0,63$ & & juv. Diab., Kinder (12) & $\begin{array}{l}\text { nüchtern, Diabetes mit Dauer: } \\
3-5, \bar{x} 3,8 \text { Jahre }\end{array}$ \\
\hline & 0,63 & & juv. Diab., Kinder (3) & $\begin{array}{l}\text { nüchtern, Diabetes mit Dauer: } \\
2-3, \bar{x} 2,3 \text { Jahre }\end{array}$ \\
\hline $\begin{array}{l}\text { Kemmler } \\
1978(143)\end{array}$ & $0,35(0,18-0,54)$ & & Normalpersonen (10) & nüchtern \\
\hline $\begin{array}{l}\text { Kuzuya et al. } \\
1978 \text { (37) }\end{array}$ & $\begin{array}{l}0,64 \pm 0,27(\text { (SD) } \\
0,15 \pm 0,13(\text { SD) } \\
0,54 \pm 0,18 \text { (SD) } \\
0,57 \pm 0,14 \text { (SD) } \\
1,46 \pm 0,39 \text { (SD) } \\
0,63 \pm 0,3 \text { (SD) } \\
2,23 \pm 1,15 \text { (SD) } \\
1,48 \pm 0,1 \text { (SD) }\end{array}$ & & $\begin{array}{l}\text { Normalpersonen (27) } \\
\text { juv. Diabetiker (12) } \\
\text { Altersdiabetiker (19) } \\
\text { Altersdiabetiker (16) } \\
\\
\text { Lebererkrankung (12) } \\
\text { Niereninsuffizienz (7) } \\
\text { Insulinom-Patient (3) }\end{array}$ & $\begin{array}{l}\text { nüchtern } \\
\text { nüchtern } \\
\text { nüchtern, normalgewichtig } \\
\text { nüchtern, übergewichtig } \\
\text { nüchtern } \\
\text { nüchtern } \\
\text { nüchtern, Hämodialyse } \\
\text { nüchtern }\end{array}$ \\
\hline $\begin{array}{l}\text { Hedtmann } \\
\text { \& Grüneklee } \\
1978(144)\end{array}$ & $\begin{array}{l}0,78 \pm 0,28(S D) \\
1,77 \pm 0,69(S D) \\
0,29 \pm 0,31(S D)\end{array}$ & & $\begin{array}{l}\text { Normalpersonen (8) } \\
\text { Altersdiabetiker (5) } \\
\text { Insulinpfl. Diab. (5) }\end{array}$ & $\begin{array}{l}\text { nüchtern } \\
\text { nüchtern } \\
\text { nüchtern }\end{array}$ \\
\hline $\begin{array}{l}\text { Kaneko } \\
1977(38)\end{array}$ & $0,42 \pm 0,1$ & & Normalpersonen (195) & nüchtern \\
\hline \multirow[t]{3}{*}{$\begin{array}{l}\text { Krause et al. } \\
1979 \text { (156) }\end{array}$} & $\begin{array}{l}0,8 \pm 0,07(\mathrm{SEM}) \\
0,25 \pm 0,03(\mathrm{SEM}) \\
1,59 \pm 0,16(\mathrm{SEM}) \\
0,95 \pm 0,13(\mathrm{SEM})\end{array}$ & & $\begin{array}{l}\text { Normalpersonen (32) } \\
\text { Normalpersonen (32) } \\
\text { Insulinpfl. Altersdiab. (10) } \\
\text { Insulinpfl. Altersdiab. (10) }\end{array}$ & $\begin{array}{l}\text { nüchtern } \\
120 \text { min nach } 0,15 \mathrm{U} \text { Insulin iv } \\
\text { nüchtern } \\
120 \text { min nach } 0,15 \mathrm{U} \text { Insulin iv }\end{array}$ \\
\hline & $1,76 \pm 0,16(\mathrm{SEM})$ & & $\begin{array}{l}\text { Sulfonylharnstoff- } \\
\text { behand. Diabetiker (10) }\end{array}$ & nüchtern \\
\hline & $0,82 \pm 0,13(\mathrm{SEM})$ & & $\begin{array}{l}\text { Sulfonylharnstoff- } \\
\text { behand. Diabetiker (10) }\end{array}$ & 120 min nach $0,15 U$ Insulin iv \\
\hline $\begin{array}{l}\text { Kaspar et al. } \\
1978(145)\end{array}$ & $\begin{array}{l}0,59 \pm 0,12 \\
1,03 \pm 0,56 \\
1,83 \pm 1,23\end{array}$ & & $\begin{array}{l}\text { Normalpersonen (7) } \\
\text { komp. Niereninsuff. (5) } \\
\text { dekomp. Nierenins. (7) }\end{array}$ & $\begin{array}{l}\text { nüchtern } \\
\text { nüchtern } \\
\text { nüchtern, Hämodialyse }\end{array}$ \\
\hline $\begin{array}{l}\text { Heding } \\
1977(120)\end{array}$ & $\begin{array}{l}0,38 \pm 0,11(\mathrm{SD}) \\
1,67 \pm 0,55(\mathrm{SD}) \\
0,54 \pm 0,55(\mathrm{SD}) \\
1,54 \pm 0,94(\mathrm{SD}) \\
0,24 \pm 0,12(\mathrm{SD}) \\
0,44 \pm 0,3 \text { (SD) }\end{array}$ & $\begin{array}{l}0,009 \pm 0,005(\mathrm{SD}) \\
0,052 \pm 0,023(\mathrm{SD}) \\
0,022 \pm 0,034(\mathrm{SD}) \\
0,046 \pm 0,022(\mathrm{SD}) \\
0,01 \pm 0,009(\mathrm{SD}) \\
0,032 \pm 0,022(\mathrm{SD})\end{array}$ & $\begin{array}{l}\text { Normalpersonen (24) } \\
\text { Normalpersonen (24) } \\
\text { Altersdiabetiker (9) } \\
\text { Altersdiabetiker (9) } \\
\text { juv. Diabetiker (10) } \\
\text { juv. Diabetiker (10) }\end{array}$ & $\begin{array}{l}\text { nüchtern } \\
1 \mathrm{~h} \text { nach Glucose }(1,75 \mathrm{~g} / \mathrm{kg}) \\
\text { nüchtern } \\
1 \mathrm{~h} \text { nach Glucose }(1,75 \mathrm{~g} / \mathrm{kg}) \\
\text { nüchtern } \\
1 \mathrm{~h} \text { nach Glucose }(1,75 \mathrm{~g} / \mathrm{kg})\end{array}$ \\
\hline $\begin{array}{l}\text { Jaspan et al. } \\
1977 \text { (27) }\end{array}$ & $\begin{array}{l}0,685 \pm 0,077(S D) \\
3,354 \pm 0,605(S D)\end{array}$ & $\begin{array}{l}0,016 \pm 0,001(\mathrm{SEM}) \\
0,121 \pm 0,028(\mathrm{SEM})\end{array}$ & $\begin{array}{l}\text { Normalpersonen (44) } \\
\text { chron. Niereninsuff. (6) }\end{array}$ & $\begin{array}{l}\text { nüchtern } \\
\text { nüchtern }\end{array}$ \\
\hline $\begin{array}{l}\text { Turner \& Heding } \\
1977(134)\end{array}$ & 0,27 & $0,042-4,2$ & Insulinom-Pat. (15) & nüchtern \\
\hline $\begin{array}{l}\text { Heding \& Ludvigson } \\
1977 \text { (146) }\end{array}$ & $\begin{array}{l}\text { nachweisbar in } \\
26 \% \text { von } n=73\end{array}$ & $\begin{array}{l}0,009 \pm 0,008 \\
0,055 \pm 2,0 \\
\text { nachweisbar in } \\
42 \% \text { von } n=73\end{array}$ & $\begin{array}{l}\text { Normalpersonen (38) } \\
\text { juv. Diabetiker ( } 73 \text { ) }\end{array}$ & $\begin{array}{l}\text { nüchtern } \\
\text { nüchtern }\end{array}$ \\
\hline $\begin{array}{l}\text { Heding } \\
1978(21)\end{array}$ & $0,39(0,18-0,79)$ & $\begin{array}{l}0,014(0-0,034) \\
1,2 \quad(0,1-9,4)\end{array}$ & $\begin{array}{l}\text { Normalpersonen (46) } \\
\text { juv. Diabetiker (24) }\end{array}$ & $\begin{array}{l}\text { nüchtern } \\
\text { nụchtern }\end{array}$ \\
\hline \multirow[t]{4}{*}{$\begin{array}{l}\text { Heding \& Persson } \\
1978 \text { (126) }\end{array}$} & $0,76 \pm 0,56(S D)$ & $0,048 \pm 0,069(S D)$ & Insulinpfl. Mütter (12) & $\begin{array}{l}\text { Geburtstermin, keine Insulin- } \\
\text { Antikörper }\end{array}$ \\
\hline & $0,94 \pm 1,1 \quad(S D)$ & $0,173 \pm 0,202(S D)$ & $\begin{array}{l}\text { Neugeborene } \\
\text { obigẹr Mütter (12) }\end{array}$ & $\begin{array}{l}\text { Geburtstermin, keine Insulin- } \\
\text { Antikörper }\end{array}$ \\
\hline & $0,04 \pm 0,01(S D)$ & $\begin{array}{l}\text { nachweisbär nur bei } \\
50 \% \text { von } n=8\end{array}$ & Insulinpfl. Mütter (8) & $\begin{array}{l}\text { Geburtstermin, Insulin- } \\
\text { Antikörper vorhanden }\end{array}$ \\
\hline & $1,13 \pm 0.79(S D)$ & $2,11 \pm 2,496(\mathrm{SD})$ & $\begin{array}{l}\text { Neugeborene } \\
\text { obiger Mütter ( } 8 \text { ) }\end{array}$ & $\begin{array}{l}\text { Geburtstermin, Insulin- } \\
\text { Antikörper vorhanden }\end{array}$ \\
\hline $\begin{array}{l}\text { Heding \& Sẹstọft } \\
1978(147)\end{array}$ & $\begin{array}{l}0,69 \\
1,08 \\
0,79 \\
1,15\end{array}$ & $\begin{array}{l}0,027 \\
0,043 \\
0,049 \\
0,124\end{array}$ & $\begin{array}{l}\text { Normalpersonen (5) } \\
\text { Normalpersonen (5) } \\
\text { Hyperthyreotiker (6) } \\
\text { Hyperthyreotiker (6) }\end{array}$ & $\begin{array}{l}\text { nüchtern } \\
1 / 2 \text { Stunde postprandial } \\
\text { nüchtern } \\
1 / 2 \text { Stunde postprandial }\end{array}$ \\
\hline
\end{tabular}




\section{Proinsulin}

Erste Messungen der Vorstufe des Insulins, des Proinsulins, basierten auf der Möglichkeit, Proinsulin aufgrund seines höheren Molekulargewichts $\left(M_{\mathrm{r}} 9000\right)$ vom Insulin $\left(M_{\mathrm{r}} 6000\right)$ und C.Peptid $\left(M_{\mathrm{r}} 3000\right)$ durch Gelfiltration abzutrennen und durch Insulin-Antiseren oder C-Peptid-Antiseren nachzuweisen $(63,103,104$, $107,108,119,120)$. Gelfiltrationsmethoden sind aufgrund des methodischen Aufwandes und der benötigten großen Probenmengen (4-5 ml) für Routinemessungen ungeeignet. Außerdem zeigen bestimmte Antiseren unterschiedliche Affinität zu Insulin und Proinsulin, was bei Verwendung von Insulinstandards im Testsystem zu falschen Proinsulinwerten führt. Kitabchi et al. (121) teilten eine Methode mit, bei der Insulin durch eine spezifische Protease zerstört und das verbleibende Proinsulin mit einem Insulin-Immunoassay bestimmt wird. Eine weitere Überprüfung des Tests aber ergab, daß Insulin in Abhängigkeit von seiner Konzentration nur teilweise zerstört wird und auch Proinsulin durch das verwendete Enzym angegriffen wird $(22,122)$. Eine elegante Nachweismethode für Proinsulin wurde vor kurzem von Heding (21) beschrieben. Das Prinzip des Testes ist folgendes: Insulin und Proinsulin werden an einen im Überschuß zugegebenen Insulinantikörper, der an Sepharose gekoppelt ist, gebunden und nach Inkubation abzentrifugiert, wogegen C-Peptid im Ưberstand verbleibt. Das Sediment wird mit einem C-PeptidAntiserum im Überschuß inkubiert. Der C-Antikörper verbindet sich dabei mit Proinsulin, das bereits an den an Sepharose gekoppelten Insulin-Antikörper gebunden ist. Die Konzentration des im Überstand verbleibenden nicht verbrauchten C-Peptid-Antikörpers, die der Konzentration an Proinsulin invers proportional ist, wird durch Zugabe von ${ }^{125}$ I-Tyr-C-Peptid bestimmt.

Die wesentlichen Vorteile dieses Verfahrens sind:

- der Test ist schnell und sehr sensitiv (nach Angabe von Heding können 0,01 nmol/1 Proinsulin entsprechend etwa $1 \mathrm{mU} / 1$ Insulin sicher bestimmt werden),

- die vorherige Abtrennung von C-Peptid und die Tatsache, daß nur Proinsulin sowohl an den Sepharosegekoppelten Insulin-Antikörper als auch an den CPeptid-Antikörper bindet, bedingt eine hohe Spezifität des Tests. Die limitierte Verfügbarkeit von menschlichem Proinsulin, das als Standard eingesetzt werden muß, hat bisher eine weite Anwendung des Verfahrens erschwert. Dementsprechend liegen auch noch keine Erfahrungsberich te verschiedener Arbeitsgruppen vor. Erste Messungen in unserem Labor bestätigen die Güte des Tests (45). Die in Tabelle 2 angegebenen, von der Arbeitsgruppe Heding seit 1977 erstellten ProinsulinDaten sind mit diesem Test erarbeitet.

Eine ebenfalls direkte, aber weniger sensitive Nachweismethode fïr Proinsulin wurde vor kurzem von Handelsmann (66) beschrieben.

\section{Bestimmung von B-Zellen-Peptiden}

Von den in Abbildung 2 angegebenen Verteilungsformen der B-Zellen-Peptide lassen sich die folgenden entweder direkt radioimmunologisch bestimmen oder durch Kombination verschiedener Kenngrößen berechnen:

\section{1. die Konzentration an freiem Insulin}

Sie umfaßt sowohl exogenes Rinder- und/oder SchweineInsulin, als auch - so noch vorhanden - endogenes Humaninsulin, darüber hinaus je nach Immunreaktivität des im Test verwendeten Antiserums auch geringe Mengen an Proinsulin. Eine Differenzierung dieser einzelnen Fraktionen ist bisher nur mit spezifischen Antiseren möglich.

2. die Konzentration an Gesamtinsulin bzw. - als Differenz Gesamtinsulin minus freies Insulin - die Konzentration an Antikörper-gebundenem Insulin.

Sie umfaßt die gleichen Spezies-Fraktionen wie das freie Insulin, eine Auftrennung ist auch hier in der Regel nicht möglich.

\section{3. die Konzentration an C-Peptid}

Kommerzielle Tests, die sich aber zum Teil erheblich hinsichtlich Spezifität und Sensitivität unterscheiden können, sind von mehreren Firmen auf den Markt gebracht worden.

4. die Konzentration an exogenem Rinder- und/oder Schweine-Proinsulin und - wichtiger - an endogenem Human-Proinsulin. Hierzu ist zur Zeit noch die Anwendung von chromatographischen Methoden und die Herstellung eigener Antiseren notwendig, da entsprechende, direkt im Plasma messende kommerzielle Tests bisher nicht angeboten werden.

5. die Konzentration, Berechnung von Affinität und prozentualer Sättigung der Insulin-Antikörper.

Entsprechende Methoden hierzu sind beschrieben (Ubersicht bei l.c. (70)). Die bis Ende 1978 in der Literatur mitgeteilten Daten sind in den Tabellen 1-3 zusammengefaßt.

\section{Klinische Anwendung und Aussagekraft}

Die Bedeutung der Messung der einzelnen B-ZellenPeptide für die klinische Forschung liegt auf der Hand. Im letzten Jahrzehnt ließen sich so wichtige Erkenntnisse über den Sekretionsmechanismus des Insulins bzw. seiner Vorstufen aus der B-Zelle und die Verteilung im Extrazellulärraum sowohl beim Gesunden als auch beim Diabetiker gewinnen (Ubersicht bei 1.c. $(123,124)$ ). Dennoch sind die Anwendungsmöglichkeiten zum unmittelbaren Nutzen bei der Therapie insulinpflichtiger Diabetiker noch gering. Die wesentlichen Fragen, die hier. Gegenstand der klinischen Forschung sind, sind folgende:

- hat die Einführung der hochgereinigten Insuline, die unbestritten zu einem geringeren Auftreten von Lipodystrophien und Insulinallergien geführt haben,'zu 
Tab. 3. C-Peptid und Proinsulin im Urin.

\begin{tabular}{|c|c|c|c|c|c|}
\hline Referenz & \multicolumn{2}{|c|}{$\begin{array}{l}\text { C-Peptid } \\
\text { (nmol/24 h)* } \\
\text { (nmol/g Kreatinin)** } \\
(\mathrm{nmol} / 1)^{* * *}\end{array}$} & $\begin{array}{l}\text { Proinsulin } \\
\text { (pmol/24 h) }\end{array}$ & Personen (n) & Bemerkungen \\
\hline $\begin{array}{l}\text { Constan et al. } \\
1975(35)\end{array}$ & & & $\begin{array}{l}5,0 \pm 3,5(\mathrm{SD}) \\
18,0\end{array}$ & $\begin{array}{l}\text { Normalpersonen (8) } \\
\text { Insulinom (1) }\end{array}$ & \\
\hline $\begin{array}{l}\text { Kuzuya et al. } \\
1976(68)\end{array}$ & $18,1 \pm 6^{* *}$ & & & Normalpersonen (11) & \\
\hline $\begin{array}{l}\text { Kuzuya et al. } \\
1978 \text { (37) }\end{array}$ & $\begin{array}{l}26,7 \pm 11,9^{*} \\
18,5 \pm 8,9^{* *} \\
2,6 \pm 2 * \\
3,3 \pm 3,3^{* *} \\
14,8 \pm 6,9^{*} \\
17,5 \pm 11,2^{* *} \\
21,1 \pm 11,6^{*} \\
20,1 \pm 11,6^{* *} \\
64,4 \pm 33,7^{*} \\
58,7 \pm 22,1^{* *} \\
17,2 \pm 15,6^{*} \\
39,6 \pm 28^{* *} \\
28,1 \pm 12,5^{*} \\
33,3 \pm 16,1^{* *} \\
2,6 \pm 3,3^{*} \\
15,2 \pm 16,5^{* *} \\
23,4 \pm 5,3^{*} \\
20,8 \pm 7,3^{* *}\end{array}$ & $\begin{array}{l}\text { (SD) } \\
\text { (SD) } \\
\text { (SD) } \\
\text { (SD) } \\
\text { (SD) } \\
\text { (SD) } \\
\text { (SD) } \\
\text { (SD) } \\
\text { (SD) } \\
\text { (SD) } \\
\text { (SD) } \\
\text { (SD) } \\
\text { (SD) } \\
\text { (SD) } \\
\text { (SD) } \\
\text { (SD) } \\
\text { (SD) } \\
\text { (SD) }\end{array}$ & & $\begin{array}{l}\text { Normalpersonen (26) } \\
\text { Normalpersonen (26) } \\
\text { juv. Diabetiker (12) } \\
\text { juv. Diabetiker (12) } \\
\text { Altersdiabetiker (19) } \\
\text { Altersdiabetiker (19) } \\
\text { Altersdiabetiker (16) } \\
\text { Altersdiabetiker (16) } \\
\text { Steroidbehandlung (7) } \\
\text { Steroidbehandlung (7) } \\
\text { Anorexia nervosa (6) } \\
\text { Anorexia nervosa (6) } \\
\text { Lebererkrankungen (12) } \\
\text { Lebererkrankungen (12) } \\
\text { chron. Niereninsuff. (21) } \\
\text { chron. Niereninsuff. (21) } \\
\text { Insulinom (3) } \\
\text { Insulinom (3) }\end{array}$ & $\begin{array}{l}\text { normalgewichtig } \\
\text { normalgewichtig } \\
\text { übergewichtig } \\
\text { übergewichtig } \\
\text { Hämodialyse } \\
\text { Hämodialyse }\end{array}$ \\
\hline $\begin{array}{l}\text { Horwitz et al. } \\
1977(30)\end{array}$ & $\begin{array}{c}11,9 \pm 1,3^{*} \\
0,36 \pm 0,17^{*} \\
7,9 \pm 2,3^{*}\end{array}$ & $\begin{array}{l}\text { (SEM) } \\
\text { (SEM) } \\
\text { (SEM) }\end{array}$ & & $\begin{array}{l}\text { Normalpersonen (25) } \\
\text { juv. Diabetiker (6) } \\
\text { Altersdiabetiker (12) }\end{array}$ & \\
\hline $\begin{array}{l}\text { Hedtmann \& Grüneklee } \\
1978 \text { (144) }\end{array}$ & $\begin{aligned} 15,2 & \pm 4,3^{*} \\
19,1 & \pm 8 \\
6,2 & \pm 4^{*}\end{aligned}$ & $\begin{array}{l}(\mathrm{SD}) \\
(\mathrm{SD}) \\
(\mathrm{SD})\end{array}$ & & $\begin{array}{l}\text { Normalpersonen (6) } \\
\text { Altersdiabetiker (5) } \\
\text { insulinpfl. Diabetiker (5) }\end{array}$ & \\
\hline $\begin{array}{l}\text { Kaneko } \\
1977 \text { (38) }\end{array}$ & $8,18 \pm 2,5 * * *$ & (SEM) & & Normalpersonen (10) & \\
\hline
\end{tabular}

einer generellen Herabsetzung der Antigenität der applizierten Insulins gefüht (Ubersicht bei 1.c. (59))?

- welche Bedeutung hat das Auftreten von Insulin-Antikörpern überhaupt für den Diabetiker im Hinblick auf seine Einstellbarkeit mit Insulin, die benötigten Tagesdosen, etwaige Spätkomplikationen und nicht zuletzt die Persistenz einer etwa noch vorhandenen Restfunktion der B-Zelle?

- läßt sich die endogene Restproduktion an Insulin, die nach übereinstimmender Meinung günstig für die Einstellbarkeit des Diabetikers ist, durch bestimmte Therapieschemata beeinflussen?

- Welche Konżentrationen an freiem Insulin im Plasma sind für eine gute Einstellung eines Insulin-pflichtigen Diabetikers notwendig und durch welche Therapieart lassen sie sich erreichen?

- läßt sịch die beim Diabetiker immer wieder beschriebene periphere Resistenz bei Kenntnis der Konżentrationen der B=Z̈ellen-Peptide im Plasma beeinflussen?

- welche anderen Möglichkeiten eröffnet die differenzierte Messung der B-Zellen-Peptide im Plassma?
Eine eindeutige Antwort auf die ersten beiden Fragen ist aus den in der Literatur angegebenen Daten nicht zu geben. Die Behandlung mit hochgereinigten Insulinen führt wahrscheinlich zu niedrigeren Titern an Insulin-Antikörpern; längere Verlaufsstudien und Vergleiche an genügend großen Kollektiven sind aber bisher nicht mitgeteilt.

Da auch in der nächsten Zukunft nicht mit dem Vorhandensein eines nicht antigenen Insulins zu rechnen ist, bleibt die Antwort auf die Frage nach der Wertigkeit der Insulinantikörper für die Therapie des Diabetikers weiterhin offen. Die in der Literatur bestehenden Widersprüche werden sich nur bei genauer Kenntnis der Faktoren lösen lassen, die den Assoziations-Dissoziationsprozeß am Antikörper in vivo beeinflussen.

Der in einer Reihe von Arbeiten in den letzten Jahren eindeutig belegte $(42,48-50,95,125)$ günstige Einfluß Pankreas - gemessen an peripheren C-Peptidkonzentrationen - und die Frage, ob sich das Versiegen der B-Zelle durch Therapie verzögern oder gar aufhalten läßt, rückt immer mehr in den Vordergrund des Inter- 
esses. Heding \& Persson (126) diskutierten in diesem Zusammenhang die Rolle der Insulin-Antikörper, die aufgrund ihrer hohen Bindungskapazität quasi einen Sog auf das insuffiziente Pankreas ausüben und bei schwangeren Diabetikerinnen nach Permeation durch die Placentarschranke (126) oder - zumindest im Tierversuch (127) auch über die Muttermilch - Einfluß auf das kindliche Pankreas nehmen. Antikörper im fetalen Kreislauf mit erhöhten C-Peptid-, Proinsulin- und Insulinkonzentrationen scheinen diese Auffassung zu bestätigen $(41,126,149)$. Die Hemmung der Insulinsekretion des Pankreas durch Erhöhung der peripheren Insulinkonzentrationen scheint mittlerweile gesichert (128-130). Welchen Einfluß dieser Mechanismus auf die Persistenz der endogenen Restfunktion des insuffizienten diabetischen Pänkreas hat, ist bisher unklar. Genauere Angaben lassen sich über die für eine optimale Einstellung des insulinpflichtigen Diabetikers notwendigen Konzentrationen an freiem Insulin im Plasma machen. Kuzuya et al. (131) konnten an Kollektiven gut eingestellter Diabetiker zeigen, daß die peripher meßbaren Konzentrationen an freiem Insulin im 24-Stunden-Mittel nicht unter $40 \mathrm{mU} / 1$ liegen dürfen - also etwa das 2-3fache des Normalen betragen müssen - und postprandial erheblich höhere Insulinspitzen als beim Gesunden notwendig sind. Wir konnten dies vor kurzem durch Vergleich von s.c. und i.v. Insulinapplikation bei Diabetikern mit und ohne Insulinantikörper bestätigen (72). Die Frage, in welcher Weise die Messung der B-Zellen-Peptide im Plasma unmittelbare Entscheidungshilfe bei der Wahl des therapeutisch benötigten Insulins und des individuellen Applikationsschemas geben, ist erst durch weitere Untersuchungen zu beantworten.

Eindeutiger ist die Indikation zur Messung von Insulin und vor allem C-Peptid und Proinsulin dagegen bei verschiedenen anderen Zuständen (132-138, 150-154). Die folgende, von uns modifizierte Aufstellung von Rubenstein et. al. (123) soll die wesentlichen Indikationsgebiete darstellen:

\section{Hypoglykämische Zustände}

Inselzelladenom (Suppressionstest)

Inselzelladenom beim Diabetiker

Hypoglycaemia factitia

\section{Literatur}

1.Oyer, P. E., Cho, S., Peterson, D. H. \& Steiner, D. F (1971) J. Biol. Chem. 246, 1375-1386.

2. Kemmler, W. \& Steiner, D. F. (1970) Biochem. Biophys. Res. Commun. 41, 1223-1230.

3. Kemmler, W., Peterson, J. D. \& Steiner, D. F. (1971) J. Biol. Chem. 246, 6786-6791.

4. Porte, D. jr. \& Bagdaded, J. (1970) Annu. Rev. Med. 21, 219-240.

5. Rubenstein, A. H., Clark, J. L., Melani, F. \& Steiner, D. F. (1969) Nature 224, 697-699.

\section{Euglykämische Zustände}

Nachweis der Remissionsphase beim Diabetiker

Hyperglykämische Zustände

Verlauf nach Pankreatektomie

„Brittle diabetes“

Die Differentialdiagnose des Insulinoms wird durch folgende Suppresșionsteșts erleichtert:

- Suppressionsversuch mit Schweine-Insulin und nachfolgende Messung des C-Peptids (132)

- Suppressionsiversuch mit Fisch-Insulin, das nicht mit Schweine- oder Rinder-Antiinsulinserum kreuzreagiert, und nachfolgender Messung von Insulin oder besser CPeptid und/oder Proịnsulin $(133,134)$.

Dies gilt auch für die Diagnose der seltenen Fälle von Insulinomen bei Diabetikern. Die Messung von CPeptid und/oder Proinsulin ist darüber hinaus hilfreich in Fällen, in denen z. B. in suicidaler Absicht Insulin injiziert wurde (hypoglycaemia factitia) sowie bei Hypoglykämien anderer Genese (135-138).

\section{Schlußfolgerung}

Für die Bestimmung der einzelnen B-Zellen-Peptide gilt, was für alle Methoden innerhalb der Klinischen Chemie generell und für radioimmunologische Methoden im. besonderen gilt (157): Direkt vergleichbare Ergebnisse der einzelnen Laboratorien werden erst zu erreichen sein, wenn es gelingen sollte, hinsichtlich Standardisierung der wesentlichen Testkomponenten - verwendete Antiseren, Standards und Tracer - wenn schon nicht Einigung zu erzielen, so doch einheitliche Kriterien zu erarbeiten. Da das gesamte beschriebene Gebiet methodisch noch sehr in Fluß ist, sind die veröffentlichten Ergebnisse wesentlich durch die jeweils verwendete Methodik beeinflußt und daher auch unter diesem Vorbehalt žu bewerten.

6. Horwitz, D. L., Starri, J. I., Mako, M. E., Blackard, W. G. \& Rubenstein, A. H. (197.5) J. Clin. Invest. 55, 1278-1283. 7. Field, J. B. (1973) Annu. Rev. Med. 24, 309-314.

8. Turner, R. G., Grayburn, J. A., Newman, G. B. \& Nabarro, J. D. N. (1971) J. Clin. Endocrinol. 33, 279-286.

9. Kaden, M., Harding, P. \& Fiëld, J. B. (1973) J. Clin. Invest. $52,2016-2028$.

10. Misbin, R. I., Merimee, T. J. \& Lowenstein, J. M. (1976) Am. J. Physiol. 230, 171-177.

11. Kühl, C., Faber, O. K., Hornnes, P. \& Jensen, S. L. (1978) Diabetes 27 (Suppl. 1), 197-200. 
12. Stoll, R. W., Touber, J. L., Menahan, L. A. \& Williams (1970) Proc. Soc. Exp. Biol. Med. 133, 894-896.

13. Sherwin, R. S., Kramer, K. J., Tobis, J. D., Insel, P. A., Lilienquist, J. E., Berman, M. \& Andres, R. (1974) J. Clin. Invest. 53, 1481-1492.

14. Zeleznik, A. J. \& Roth, J. (1978) J. Clin. Invest. 58, 1363-1374.

15. Starr, J. I. \& Rubenstein, A. H. (1974) J. Clin. Endocrinol. Metab. 38, 305-308

16. Sönksen, P. H., Tomkins, C. V., Srivastava, M. G. \& Nabarro, J. D. (1973) Clin. Sci. Molecul. Med. 45, 633-654.

17. McGuire, E. A., Tobin, J. D., Berman, M. \& Andres, R. (1979) Diabetes 28, 110-120.

18. Horwitz, D. L., Starr, J. I., Rubenstein, A. H. \& Steiner, D. F. (1973) Diabetes 22 (Suppl. 1), 298.

19. Kuzuya, T. \& Matsuda, A. (1976) Diabetologia 12, 519-522.

20. Faber, O. K., Kehlet, H., Madsbad, S. \& Binder, Ch. (1978) Diabetes 27 (Suppl. 1), 207-209.

21. Heding, L. G. (1978) Diabetes 27 (Suppl. 1), 178-183.

22. Duckworth, W. C. \& Kitabchi, A. E. (1976) J. Lab. Clin. Med. 88, 359-367.

23. Gordon, P., Sherman, B: \& Roth, J. (1971) J. Clin. Invest. 50, 2113-2122.

24. Gordon, P., Roth, J., Hendricks, C. M. \& Kahn, C. R. (1974) Isr. J. Med. Sci. 10, 1212-1221.

25. Gordon, P., Hendricks, C. M. \& Roth, J. (1974) Diabetologia 10, 469-474.

26. Kitabchi, H. E., Colwell, J. A. \& Duckworth, W. C., zitiert nach l.c. (124).

27. Jaspan, J. B., Mako, M. E., Kuzuya, H., Blix, P. M., Horwitz, D. L. \& Rubenstein, A. H. (1977) J. Clin. Endocrinol. Metab. 45, 441-446.

28. Fink, G., Cresto, J. G., Gutman, R. A., Lavine, R. L., Rubenstein, A. H. \& Recant, L. (1974) Horm. Metab. Res. 6, 439-443.

29. Gabby, K. H., Deluca, K., Fisher, J. N. jr., Mako, M. E. \& Rubenstein, A. H. (1976) N. Engl. J. Med. 294, 911-915.

30. Horwitz, D. L., Rubenstein, A. H. \& Katz, A. I. (1977) Diabetes 26, 30-35.

31. Jörgensen, K. B. R. (1966) Acta Endocrinol (Kbh.) 51, $400-410$.

32. Rubenstein, A. H., Lowy, C. \& Fraser, T. R. (1967) Diabetologia 3, 453-459.

33. Rubenstein, A. H. \& Spitz, J. (1968) Diabetes 17, 161-169.

34. Lowy, C. \& Schiff, D. (1968) Lancet $I, 225-227$.

35. Constan, L., Mako, M., Juhn, D. \& Rubenstein, A. H. (1975) Diabetologia 11, 119-123.

36. Kuzuya, T., Matsuda, A., Saito, T. \& Yoshida, S. (1976) Diabetologia 12, 511-518.

37. Kuzuya, T., Matsuda, A., Sakamoto, Y., Tanabschi, S. \& Kajenuma, H. (1978) Diabetes 27 (Suppl. 1), 210-215.

38. Kaneko, T., Munemura, M., Oka, H., Oda, T., Suzuki, H., Yasuda, H., Yanaihara, N., Nakagawa, S. \& Makebe, K. (1975) Endocrinol. Jap. 22, 207-212.

39. Grüneklee, D., \& Hedtmann, A. (1977) Proc. I. Int. Symposion on C-peptide, Mainz, Germany 161-167.

40. Ludvigson, L. \& Heding, L. G. (1978) Diabetes 27 (Suppl. 1), 230-234.

41. Block, M. B., Pildes, R. S., Mossabhoy, N. A., Steiner, D. F. \& Rubenstein, A. H. (1974) Pediatrics 53, 923-928.

42. Grajwer, L. A., Pildes, R. S., Horwitz, D. L. \& Rubenstein, A. H. (1977) J. Pediatr. 90, 42-48.

43. Ludvigsson, J. \& Heding, L. G (1976) Diabetologia 12, $627-630$.

44. Ludvigson, J. \& Heding, L. G. (1977) Acta Endọcrinol. (Kbh.) 85, 364-371.

45. Kèmmler, W. \& Gerbitz, K.-D. (1979) unveröffentlichte Beobachtung.

46. Block, M. B., Mako, M. E., Steiner, D. F. \& Rubenstein, A. H. (1972) J. Clin. Êndocrinól. Metab. 35, 402-406.

47. Beischer, W., Raptis, S., Keker, L., Heinze, E., Schịöder, K. E. \& Pfeiffer, E. F. (1975) 11th Annu. Meet. Europ. Assoc. Study Diabetes, Munich. Diabetologia $11,332$.

48. Heinze, E., Beischer, W., Keller, L., Winkler, G., Tèller, W. M. \& Pfeiffer, E. F. (1978) Diabetes 27, 670-676.

49. Binder, Ch. \& Faber, O. K. (1978) Diabetes 27 (Suppl. 1), 226-229.
50. Gerbitz, K.-D., Kemmler, W., Edelmann, A., Summer, J., Mehnert, H. \& Wieland, O. H. (1979) Europ. J. Clin. Invest. 9, 475-483.

51. Lawrence, R. D. (1926) British Med. J. I, 648-652.

52. Bürger, M. \& Kramer, H. (1928) Klin. Wochenschr. 7, 745-750.

53. Binder, Ch. (1969) Acta Pharmacol. Toxicol. 27 (Suppl. 2), $1-87$.

54. Koivisto, V. A. \& Felig, P. (1978) N. Engl. J. Med. 298, 77-83.

55. Berger, M., Halbau, P. A., Girardier, L., Seydoux, J., Offord, R. E. \& Reynold, A. E. (1978) 13. Kongr. Dt. Diabetes-Ges., Düsseldorf, Abstract Nr. 5.

56. Berger, M., Halbau, P. A., Assal, J. P., Offord, R. E., Vramic M. \& Reynold, A. E. (1979) Diabetes 28 (Suppl. 1), 53-57.

57. Schlichtkrull, J. (1977) Acta Paediatr. Scand. Suppl. 270, 97-101.

58. Bloom, S. R., Adrian, T. E., Mitchell, S. J., Barnes, A. J. \& Kohner, E. M. (1976) Diabetologia 12, 381-385.

59. Alberti, K. G. M. M. \& Nattrass, M. (1978) Diabetologia $15,77-80$.

60. De Häen, Ch., Little, S. A., May, J. M. \& Williams, R. H. (1978) J. Clin. Invest. 62, 727-737.

61. Rubenstein, A. H., Kuzuya, H. \& Horwitz, D. L. (1977) Arch. Int. Med. 137, 625-632.

62. Rubenstein, A. H., Mako, M. E., Welbourne, W. P. (1970) Diabetes 19, 546-553.

63. Heding, L. G., Larsen, U. D., Markussen, J., J $\phi$ rgensen, K. H. \& Hallund, O. (1974) Horm. Metab. Res. 5 (Suppl.) 40-44.

64. Berson, S. A. \& Yalow, R. S. (1959) J. Clin. Invest. 38, 1996-2016.

65. Kurtz, A. B., Matthews, J. A. \& Narrabo, J. D. N. (1978) Diabetologia 15, 19-22.

66. Handelsman, D. J. (1979) Xth Congr. Int. Diab. Fed. Vienna, Abstract $214 \mathrm{P}$.

67. Block, M. B., Mako, M. E., Steiner, D. F. \& Rubenstein, A. H. (1972) Diabetes 21, 1013-1026.

68. Kuzuya, H., Blix, P. M., Horwitz, D. L., Steiner, D. F. \& Rubenstein, A. H. (1977) Diabetes 26, 22-29.

69. Gennaro, W. D. \& Van Norman, J. D. (1975) Clin. Chem $21,873-879$.

70. Gerbitz, K.-D. \& Kemmler, W. (1978) Clin. Chem. 24, 890-894.

71. Gerbitz, K.-D., Kemmler, W. \& Wieland, O. H. (1979) J. Clin. Chem. Clin. Biochem. 17, 153.

72. Gerbitz, K.-D., Kemmler, W., Edelmann, A., Hepp, K. D. \& Renner, R. (1979) C-Peptid-Symposion, Düsseldorf (Grüneklee, D. \& Herzog, W. eds.) Schnetztor-Verlag, Konstanz, pp. 105-115.

73. Asplin, C. M., Goldie, D. J. \& Hartog, M. (1977) Clin. Chim. Acta 75, 393-399.

74. Heding, L. G. (1969) Horm. Metab. Res. 1, 145-146.

75. Yalow, R. S. (1976) In: „Insulin“" (Luft, R. ed.) 149-196. A. Lindgreen \& Söner, A. M., Mölndal, Sweden.

76. Yue, D. K., Baxter, R. C. \& Turtle, J. R. (1976) Biochim. Biophys. Acta 444, 231-239.

77. Goldman, J., Baldwin, D., Pugh, W. \& Rubenstein, A. H. (1978) Diabetes 27, 653-660.

78. Dixon, K., Exon, P. D. \& Hughes, H. R. (1972) Lancet $I$, 343-347.

79. Dixon, K. (1974) Clin. Chem. 20, 1275-1280.

80. Jackson, P. A. \& Dixun, K. (1977) J. Immunol. Meth. 1, 201-211.

81. Anderson, O. O. (1972) Acta Endocrinol. (Kbh.) 71, 126-140.

82. Anderson, O. O. (1975) Acta Endocrinol. (Kbh.) 78, 723-735.

83. Devlin, J. G. \& Brien, T. G. (1965) Metabolism 14, 1034-1036.

84. Kerp, L., Kasimier, H. \& Kieling, F. (1968) Klin. Wochenschr. 46, 3976-3985.

85. Andreani, D., Iavicoli, M., Tamburrano, G. \& Menzinger, G. (1974) Horm. Metab. Res. 6, 447-454.

86. Andersen, O. O. \& Egeberg, J. (1977) Acta Paediatr. Scand. Suppl. 270, 63-68.

87. Oakiley, N. W. (1976) Lancet $I, 994-996$.

88. Sebriakowa, M. \& Little, J. A. (1973) Diabetes 22, 30-40.

89. Little, J. A., Lee, R., Sebriakowa, M. \& Csima, A. (1977)

Diabetes 26, 980-988. 
90. Yue, D. K., Baxter, R. G. \& Turtle, J. R. (1978) Metabolism $27,35-44$

91. Baxter. R. C., Yue, D. K. \& Turtle, J. R. (1976) Clin. Chem. 22, 1089-1094.

92. Yue, D. K. \& Turtle, J. R. (1977) Diabetes 26, 341-345.

93. Tantillo, J. J., Karam, J. H., Burik, K. C., Jones, M. A., Grodsky, G. M. \& Forsham, P. H. (1974) Diabetes 23, 276-281.

94. Scott, R. S., Espiner, E. A., Donald, R. A. \& Smith, J. R. (1978) Diabetes 27, 1151-1155.

95. Shima, K., Tanaka, R., Morishita, S., Tarui, S., Kumahara, Y. \& Nishikaiva, M. (1977) Diabetes 26, 717-725.

96. Chance, R. E., Root, M. A. \& Galloway, J. A. (1975) Acta Endocrinol. (Kbh.) Suppl. 205, 185-196.

97. Stout, R. W. (1979) Diabetologia 16, 141-150 (1979).

98. Goodner, C. J. \& Porte, D. jr. (1972) In: Handbook of physiology, Section 7, pp. 597-609, Washington DC: Am. Physiol. Soc.

99. Desbuquois, B. \& Aurbach, G. D. (1971) J. Clin. Endocrinol. $33,732$.

100. Desbuquois, B. \& Aurbach, G. D. (1972) Biochem. J. 126, 717-726.

101. Nakagawa, S., Nakayama, H., Sasaki, T., Yeshino, K., Yu, Y. Y., Shinozaki, K., Aoki, S. \& Mashimo, K. (1973) Diabetes 22, 590-600.

102. Kolb, H. J. \& Standl, E. (1975) Proc. IX. Annu. Meet. Europ. Soc. Clin. Invest., Rotterdam, Abstract p. 55.

103. Melani, F., Rubenstein, A. H., Oyer, P. E. \& Steiner, D. F. (1970) Proc. Nat. Acad. Sci. USA 67, 148-155.

104. Kaneko, T., Oka, H., Manemura, M., Oda, T., Yamashita, K., Suzuki, S., Yanaihara, N., Hashimoto, T. \& Yanaihara, C. (1974) Endocrinol. Jap. 21, 141-145.

105. Faber, O. K., Markassen, J., Naithani, V. K. \& Binder, Ch. (1976) Hoppe-Seylers Z. Physiol. Chem. 357, 751-757.

106. Heding, L. G. \& Rasmussen, S. M. (1975) Diabetologia 11 201-206.

107. Heding, L. G. (1975) Diabetologia 11, 541-548.

108. Beischer, W., Keller, L., Maas, M., Schiefer, E. \& Pfeiffer, E. F. (1973) Klin. Wochenschr. 54, 709-715

109. Faber, O. K., Binder, C., Markussen, J., Heding, L. G., Naithani, V. K., Kuzuya, H., Blix, P., Horwitz, D. \& Rubenstein, A. H. (1978) Diabetes 27 (Suppl. 1), 207-209.

110. Kuzuya, H., Blix, P. M., Horwitz, D., Rubenstein, A. H., Steiner, D. F., Binder, Ch. \& Faber, O. K. (1977) J. Clin. Endocrinol. Metab. 44, 952-962.

111. Kuzuya, H., Blix, P. M., Horwitz, D. L., Rubenstein, A. H. \& Steiner, D. F. (1978) Diabetes 27 (Suppl. 1) 184-191.

112. Heding, L. G., Larsen, U. D., Markussen, J. \& Naithani, V. K. (1975) Diabetologia 11, 348, Abstract.

113. Naithani, V. K. (1973) Horm. Metab. Res. 5, 53.

114. Naithani, V. K. (1973) Hoppe-Seyler's Z. Physiol. Chem. $354,659-672$.

115. Naithani, V. K., Dechesne, M., Markussen, J., Heding, L. G. \& Larsen, U. (1975) Hoppe-Seyler's Z. Physiol. Chem. 356, 1305-1312.

116. Geiger, R., Jäger, G. \& König, W. (1973) Chem. Ber. 106, 2347-2352.

117. Kuzuya, H., Chance, R. E., Steiner, D. F. \& Rubenstein, A. H. (1978) Diabetes 27 (Suppl. 1), 161-169.

118. Yanaihara, N., Yanaihara, C., Sakagami, M., Sakura, N., Hashimoto, T. \& Nishida, T. (1978) Diabetes 27 (Suppl. 1), $149-160$.

119. Gordon, P. \& Roth, J. (1969) J. Clin. Invest. 48, 2225-2234.

120. Heding, L. G. (1977) Diabetologia 13, 467-474.

121. Kitabchi, A. E., Duckworth, W. C., Brush, J. S. \& Heinemann M. (1971) J. Clin. Invest. S0, 1792-1799.

122. Starr, J. I., Juhn, D. D., Rubenstein, A. H. \& Kitabchi, A. E. (1975) J. Lab. Clin. Med. 86, 631-637.

123. Rubenstein, A. H., Steiner, D. F., Horwitz, D. L., Mako, M. E., Block, M. B., Starr, J. I., Kuzuya, H. \& Melani, F. (1977) Rec. Progr. Horm. Res. 33, 435-475.

124. Kitabchi, A. E. (1977) Metabolism 26, 547-587.

125. Beischer, W., Heinze, E., Keller, L., Raptis, S., Kerner, W \& Pfeiffer, E. F. (1976) Klin. Wochenschr. 54, 7.17-725.

126. Heding, L. G. \& Persson, B. (1978) XIV Annu. Meet. Europ. Assoc. Study Diabetes. Zagreb, Abstract p. 238.
127. Neubauer, H. P. \& Schoene, H. H. (197.8) XIV Annu. Meet. Europ. Assoc. Study Diabetes. Zagreb, Abstract p. 258.

128. Horwitz, D. L., Rubenstein, A. H., Reynolds, C., Molnar, G. D. \& Yanaihara, N. (1975) Horm. Metab. Res. 7, 449-452.

129. Beischer, W., Schmid, M., Kerner, W., Keller, L. \& Pfeiffer, E. F. (1978) 13. Kongr. Dt. Diabetes-Ges., Düsseldorf, Abstrakt 4, Teil A.

130. Liljenquist, J. E., Horwitz, D. L., Jennings, A. S., Chiasson, J.-L., Keller, U. \& Rubenstein, A. H. (1978) Diabetes 27, 563-570.

131. Lewis, S. B., Wallin, J. D., Kuzuya, H., Murray, W. K., Constan, D. R., Daane, T. A. \& Rubenstein, A. H. (1976) Diabetologia 12, 343-350.

132. Horwitz, D. L., Rubenstein, A. H., Mako, M. E., Cruz, A. Blix, B. S. (1978) Diabetes 27 (Suppl. 1), 267-271.

133. Turner, R. C. \& Johnson, P. C. (1973) Lancet $I, 1483-1485$.

134. Turner, R. C. \& Heding, L. G. (1977) Diabetologia 13, 571-577.

135. Scarlett, J. A., Mako, M. E., Rubenstein, A. H., Blix, P. M., Goldman, J., Horwitz, D. L., Tager, H., Jaspan, J. B., Stjernholm, M. R. \& Olefsky, J. M. (1977) N. Engl. J. Med. 297, 1029-1032.

136. Kurtz, A. B., Harrington, M. G., Mat thews, J. A. \& Nabarro, J. D. N. (1979) Diabetologia 16, 65-67

137. Service, F. D., Rubenstein, A. H. \& Horiwitz, D. L. (1975) May o Clinic Proc. 50, 697-701.

138. Couropmitree, C, Freinkel, N., Nagel, T. C., Horwitz, D. L., Metzger, B., Rubenstein, A. H. \& Hahnel, R. (1975), Annu. Intern. Med. 82, 201-204.

139. Krause, U., Cordes, U. \& Beyer, J. (1977) Dtsch. Med. Wochenschr. 102, 785-790.

140. Faber, O. K. \& Binder, C. (1977) Diabetes 26, 605-610.

141. Faber, O. K. \& Binder, C. (1977) in: Diabetes, Proc. IX Congr. Int. Diabetes Fed. (J. S. Bajaj, ed.), 149-154. Excerpta Med. Oxford-Amsterdam.

142. Faber, O. K., Hagen, C., Binder, C., Markussen, J., Naithani, V. K., Blix, P. M., Kuzuya, H., Horwitz, D. L., Rubenstein, A. H. \& Rossing, N. (1978) J. Clin. Invest. 62, 197-203.

143. Kemmler, W. (1978) unveröffentlichte Ergebnisse.

144. Hedtmann, A. \& Grünklee, D. (1978) XIV. Annu. Meet. Europ. Assoc. Study Diabetes, Zagreb, Abstract p. 238.

145. Kaspar, C., Beischer, W., Maas, M., Keller, L., Franz, E. \& Pfeiffer, E. F. (1978) 13. Kongr. Dt. Diabetes-Ges., Düsseldorf, Abstrakt Nr. 18, Teil B.

146. Heding, L. G. \& Ludvigsson, J. (1977) Acta Paediatr. Scand. Suppl. 270, 48-52.

147. Heding, L. G. \& Sestoft, L. (1978) 38th Annu. Meet. Amer. Diabetes Assoc., Boston, Abstract p. 480.

148. Olefsky, J. M. \& Reaven, G. M. (1977) Diabetes 26, 680-688.

149. Ludvigsson, J. \& Heding, L. G. (1978) Diabetes 27 (Suppl. 1), 230-234.

150. Schein, P. S., De Lellis, R. A., Kahn, C. R., Gordon, P. \& Kraft, A. R. (1973) Ann. Intern. Med. 79, 239-257.

151. Blackward, W. G., Garcia, A. R. \& Brown, C. L. (1970) J. Clin. Endocrinol. Metab. 31, 215-219.

152. Alsever, R. N., Roberts, J. P., Gerber, J. G., Mako, M. E. \& Rubenstein, A. H. (1975) Ann. Intern. Med. 82, 347-350.

153. Rubenstein, A. H., Mako, M. E., Starr, J. I., Juhn, D. J. \& Horwitz, D. L. (1974) in: Proceedings of the XI Congr. Congr. Int. Diabetes Fed., Ser. 312 (Malaisse, W. J. \& Pirart, $J$. (eds.)), Brüssel-Amsterdam, Excerpta Medica 736-752.

154. Lazarus, N. R., Tanabe, T., Gutman, R. \& Recant, L. (1970) J. Clin. Endocrinol. Metab. 30, 273-281.

155. Regeur, L., Faber, O. O. \& Binder, C. (1978) Scand. J. Clin. Lab. Invest. 38, 771-775.

156. Krause, U., Faisset, G., Cordes, U. \& Beyer, J. (1979) Horm. Metab. Res. 11, 261-265.

157. Marschner, I., Bottermann, P., Erhardt, F., Lincke, R., Löffler, G., Maier, V., Schwandt, P., Vogt, W. \& Scriba, P. C. (1974) Horm. Metab. Res. 6, 293-296.

Dr. Klaus-D. Gerbitz Klin.-chem. Institut Krankenhaus München-Schwabing Kölner Platz 1 D-8000 München 40 . 